\title{
Der Wanderer und sein Schatten
}

Im Folgenden werden die Methode sowie der Forschungsstand zur Schreibthematik bei Nietzsche und zum Wanderer vorgestellt (2.1). Dabei gilt es einige Probleme und Eigenheiten zu beachten, die sich bei der Arbeit mit Nietzsches Manuskripten und Editionen ergeben. Danach werden Gründe für die Befangenheit der Wanderer-Rezeption aufgeführt und problematisiert (2.2). Schliesslich werden als Grundlage für alle weiteren Kapitel die Schreibsituation und Entstehungsgeschichte des Wanderers beschrieben (2.3).

\subsection{Methode und Forschungsstand}

Die Analyse von philosophischen Schreibtechniken erfährt mittlerweile grosses Interesse. ${ }^{1}$ Insbesondere die Manuskripte gelangen vermehrt als digitalisierte Faksimile in Umlauf und können auch abseits von Archiven untersucht werden. In der Nietzscheforschung versuchen zwei Projekte die Manuskripte differenziert zu edieren: Zum einen das Editionsprojekt «Der späte Nietzsche», welches innerhalb der KGW IX den Nachlass von Frühjahr 1885 bis Januar 1889 «in differenzierter Transkription» veröffentlicht, zum anderen die digitale Edition Nietzsche Source (früher HyperNietzsche). ${ }^{2}$ Als Pilotprojekt der letztgenannten Edition wurden die Wanderer-Manuskripte wegen der relativ vollständigen Überlieferungslage digitalisiert, ediert und ab 2000 nach und nach im Internet veröffentlicht. ${ }^{3}$ Es handelt sich um ein «genetisches Dossier», das

1 Vgl. stellvertretend folgende Publikationen über philosophisches Schreiben: zu Kant (Karl 2007 und Kammer 2017); zu Jacobi (Ortlieb 2010 und 2015); zu Cassirer (Schubbach 2016); zu Lichtenberg (McGillen 2016); zu Schopenhauer (Kammer 2010). Einen wichtigen Beitrag zur Bedeutung von Notizbüchern für die wissenschaftliche und philosophische Arbeit leistet die Studie von Richard R. Yeo (2014), der u.a. anhand der Schreibverfahren von Francis Bacon und John Locke die enge Verknüpfung zwischen Schreiben, Denken und Experimentieren beschrieben hat.

2 Vgl. KGW IX, in der Nietzsches Aufzeichnungen in topographischer Darstellung gedruckt und die Faksimiles auf den beiliegenden CD-ROMs zu finden sind (vgl. Röllin/Stockmar 2007 und 2017 sowie Giuriato/Zanetti 2003). HyperNietzsche wurde im Rahmen einer Tagung der Scuola Normale Superiore di Pisa 1996 zum ersten Mal der Öffentlichkeit vorgestellt, vgl. D'Iorio/Ferrand (Hg.) 1999 .

3 Nachdem sich 1999 eine Arbeitsgruppe gebildet hatte, konnte 2000 ein erstes Buch über das Projekt veröffentlicht werden, in dem Idee, Konzept und Einbettung von HyperNietzsche

(C) WILHELM FINK VERLAG, 2019 | DOI:10.30965/9783846764053_003

This is an open access chapter distributed under the terms of the prevailing CC-BY-NC-ND License at the time of publication. 
heisst eine vollständige Manuskriptsammlung in Bezug auf ein Werk. ${ }^{4}$ Dieses «dossier génétique» war für meine Dissertation ein Glücksfall: Denn ohne die Faksimiles, die Transkriptionen und die Analyse der Vorstufenzusammenhänge, wäre dieses Forschungsprojekt kaum zu realisieren gewesen. Im Jahr 2007 wurde die HyperNietzsche-Edition aufgrund von Problemen der Bedienbarkeit und einer überarbeiteten digitalen Forschungsarchitektur durch das Projekt Nietzsche Source abgelöst. ${ }^{5}$ Das «dossier génétique» zum Wanderer blieb jedoch noch viele Jahre online abrufbar, wurde mittlerweile aber vom Netz genommen. ${ }^{6}$ Die nie vollendete genetische Edition vom Wanderer soll innerhalb von Nietzsche Source neu und vollständig im Netz veröffentlicht werden. ${ }^{7}$

\subsubsection{Methode}

Meine Vorgehensweise orientiert sich an der Critique génétique (a), der Wissenschaftsforschung (b), der Schreib- und Manuskriptforschung (c), der medientheoretischen Nietzscheforschung (d) sowie der durch Mazzino Montinari begründeten Verbindung von philologischem und philosophischem Forschen (e).

(a) Die Methode des genetischen Nachvollzugs von Schreibprozessen entstand ab den 1970er Jahren im Gefolge der Critique génétique. ${ }^{8}$ Diese Forschungsrichtung untersuchte anhand genetischer Dossiers literarische Werke und Projekte. Es dauerte lange, bis auch Manuskripte von Philosophen mit dieser Methode analysiert wurden. Stellvertretend für diesen Forschungszweig sei die 2003 erschienene Ausgabe der französischen Zeitschrift Genesis (Ma-

dargelegt werden: Vgl. Amblard/D'Iorio (Hg.) 2000. Ab 2001 war HyperNietzsche in der Version 0.1 online zugänglich. Das für diese Arbeit zentrale «dossier génétique» zum Wanderer war ab Version 0.3 zugänglich und wurde mit jeder Version um neue Features erweitert. So kamen nach und nach verschiedene Transkriptionsarten sowie Stufenapparate hinzu. 2003 wurde das entsprechende Internetportal der Online-Edition designt. Es ging HyperNietzsche um die Herstellung neuer Forschungsinstrumente. Für eine ausführliche Beschreibung vgl. Saller 2006, S. 83-85 und D'Iorio 2017.

4 Vgl. für den Begriff der genetischen Textedition: D'Iorio 2010 und 2017; Gerike 2002 (die deutsche Netzpublikation ist offline): «Mit Hilfe dieser Materialien ist es möglich, die Entstehung des Wanderers von der ersten Notiz bis zum abgeschlossenen Text zu verfolgen.» Die französische Textstelle findet sich in Gerike 2000, S. 132.

5 Vgl. zu diesem Wechsel D'Iorio 2008, S. 296-299.

6 HyperNietzsche war erreichbar unter folgender Adresse: http://www.hypernietzsche.org [12.09.2014].

7 Vgl. D'Iorio 2015, S. 17: «The genetic edition of two of Nietzsche's works: The Wanderer and his Shadow and Daybreak, including all related manuscripts is in preparation.» Zum Stand der Arbeiten vgl. D'Iorio 2017.

8 Vgl. Grésillon 1999. Für einen Überblick zur Textgenetik in der deutschen Literatur vgl. Hurlebusch 1998. 
nuscrits-Recherche-Invention) erwähnt: Paolo D'Iorio verweist darin einleitend auf drei Potenziale der philosophischen Textgenetik: Erstens auf die Analyse der Arbeitsweise eines Philosophen; zweitens auf ein komplexeres Verständnis von Philosophie, das auch Kontingenzen, Ambivalenzen und Widersprüche der Denkarbeit untersucht; und drittens auf das Entdecken und Nutzen der vielen brachliegenden Denkwege und Philosopheme, die unabhängig von ihrem nicht autorisierten Status einen philosophischen Wert haben. ${ }^{9}$ Die philosophische Textgenetik unterscheidet gezwungenermassen streng zwischen Werk und Nachlass: «Lanalyse génétique nous permet donc de reconstituer l'‘artisanat> philosophique de Nietzsche - mais elle nous oblige aussi à ne jamais confondre l'artisanat et l'œuvre à laquelle il aboutit.» ${ }^{10}$ Es wird demgegenüber zu zeigen sein, dass Nietzsche die Konfusion von Produktion und Werk im Wanderer aktiv betreibt.

(b) Die Arbeiten der Critique génétique trafen vermehrt auf Ansätze der Wissenschaftsforschung und umgekehrt. Die Wissenschaftsforschung untersucht über alle Disziplinen hinweg die Praktiken und Instrumente der Wissensproduktion, um letztere in ein Verhältnis zum dabei entstehenden Wissen zu setzen. Im Fokus der Forschung standen die Experiment- und Schreibsituationen (z.B. im Freien, im Labor, in der Bibliothek), die Schreibgeräte (z.B. Bleistift, Tinte, Schreibmaschine), die Wissensorganisationsformen (z.B. Zettelkästen, Exzerpthefte, Notizbücher) und die epistemischen Praktiken (z.B. Notieren, Skizzieren, Schreiben, Zeichnen). Im aktuellen Zusammenhang mit meiner Arbeit kann hier stellvertretend die Buchreihe Wissen im Entwurf genannt werden, welche die Ergebnisse des gleichnamigen Forschungsprojekts des Max-Planck-Instituts für Wissenschaftsgeschichte in Berlin sowie des Kunsthistorischen Instituts in Florenz versammelt. ${ }^{11}$ Zudem sind zur Untersuchung von Nietzsches Notizbüchern die wissenschaftshistorischen Studien von Christoph Hoffmann und Hans-Jörg Rheinberger nützlich, weil sie die

9 Vgl. D'Iorio 2003, bes. S. 9: «C'est peut-être là une des particularités de la génétique philosophique par rapport à la génétique littéraire, dans la mesure où la première nous livre non seulement une connaissance des processus d'écriture des œuvres, mais aussi des concepts qui, même s'ils sont détachés de l'œuvre et de sa genèse, n'en sont pas moins philosophiquement précieux.»

10 Ponton 2003, S. 87. Vgl. Maurer 1984, S. 347: «So prekär es ist, den Vorstufen eines Textes materielle Deutungshinweise für das Verständnis des späteren Produkts entnehmen zu wollen, so fruchtbar hat sich seit den Tagen Friedrich August Wolfs die Berücksichtigung der spezifischen Produktions- und Vermittlungsweise, gewissermaßen der «Natur eines Textes erwiesen, wie sie sich nicht zuletzt an seiner Entstehungs- und Überlieferungsgeschichte ablesen läßt.»

11 Die Buchreihe «Wissen im Entwurf» umfasst vier Sammelbände: Hoffmann (Hg.) 2008; Wittmann (Hg.) 2009; Krauthausen/Nasim (Hg.) 2010; Voorhoeve (Hg.) 2011. 
epistemischen Funktionen von Schreibpraktiken und Schreibzeug, insbesondere Notizbüchern, thematisieren. ${ }^{12}$

(c) Das Interesse an wissenschaftlichem und literarischem Schreiben hat mittlerweile zahlreiche interdisziplinäre Forschungsfelder hervorgebracht, allen voran das Forschungsprojekt «Zur Genealogie des Schreibens: Die Literaturgeschichte der Schreibszene von der Frühen Neuzeit bis zur Gegenwart». Dabei wurden der Schreibakt, die Schreibinszenierung und verschiedene Schreibpraktiken untersucht. Das von 2001 bis 2007 an der Universität Basel durchgeführte Projekt resultierte in der Buchreihe Genealogie des Schreibens im Wilhelm Fink Verlag. Des Weiteren hat Christian Benne anhand von zahlreichen Manuskriptkonvoluten eine Theorie und Geschichte der «Manuskriptkultur» vorgelegt. ${ }^{13}$ Dabei wirft er insbesondere die lange vernachlässigte Frage auf, weshalb seit dem 18. Jahrhundert immer mehr Manuskripte aufbewahrt und archiviert wurden. Die strategische Aufbewahrungspraxis von Manuskripten ist mittlerweile durch einige Studien erforscht worden. ${ }^{14}$ Zudem liegen wichtige Publikationen über die Wechselwirkungen von Produktionsbedingungen, Buchmaterialität, Buchmarkt und Autorschaft vor. ${ }^{15}$ So wurden auch im Rahmen des Forschungsprojekts «Poetik des Materiellen» (2014-2017) an der Universität Zürich vielfältige Bezüge zwischen der Materialität des Schreibens und der Buchproduktion erforscht. ${ }^{16}$ Für die Analyse der strategischen Werkinszenierung und -vermarktung ist Steffen Martus' Studie Werkpolitik massgebend. ${ }^{17}$ All diese Projekte und Publikationen sowie die vorliegende Dissertation bestätigen die steigende Bedeutung von Materialität, Produktionsabläufen und Werkpolitik im 18. und 19. Jahrhundert.

12 Man befindet sich bei Schreibmaterialien immer in einem eigenständigen epistemischen Raum. Vgl. dazu Holmes/Renn/Rheinberger (Hg.) 2003; Rheinberger 2006, bes. S. 350-361; Rheinberger 2005; Hoffmann 2008a; Rheinberger 2011, S. 279.

13 Vgl. Benne 2015a, hier S. 159. Der Fokus auf Entstehungskontexte ist laut Benne eine Folge des neuen Blicks auf publizierte Texte, den die Manuskriptkultur eröffnet, vgl. S. 274 und S. 409: «Insbesondere die Aufwertung des Schreibens gegenüber dem Druck und damit der Manuskripte gegenüber den Publikationen brachte, so die These, eine neuartige Form literarischer Manuskriptkultur hervor, in der Begriff und Praxis des literarischen Schreibens und des literarischen Werks zunehmend an die Hervorbringung und Aufbewahrung von Handschriften als Spuren des literarischen Prozesses geknüpft wurden, dessen Genese gegenüber dem Resultat an Bedeutung gewinnt.»

14 Vgl. Martus 2007; Benne 2015a, insb. sein Kap. zu Jean Paul, S. 516-55o; Sine/Spoerhase (Hg.) 2017 .

15 Vgl. Spoerhase 2018; Ortlieb/Fuchs (Hg.) 2017 sowie den Klassiker Bosse 1981.

16 Vgl. dazu Müller-Wille 2017.

17 Vgl. Martus 2007. 
(d) Das philosophische Interesse für Nietzsches Schreibpraktiken ist insbesondere durch die radikal medientheoretische Auslegung seiner Werke befördert worden. ${ }^{18}$ Friedrich Kittler wies in zahlreichen Arbeiten auf die medial bedingte Geschichte der Philosophie hin. ${ }^{19}$ Daraus erwuchs auch die Idee, die Rolle des Materials und des Körpers zu beachten, also «eine Theorie des Schreibens mit der Physiologie statt mit den Geisteswissenschaften zu verkoppeln.» ${ }^{20}$ Zu diesem Zweck erwiesen sich Nietzsches Schreibmaschinen-Typoskripte als ergiebige Quelle. ${ }^{21}$ Sie sensibilisieren einerseits für die medialen, praktischen und materialen Bedingungen philosophischer Arbeit, andererseits für Nietzsches differenzierten, selbstreflexiven und spielerischen Umgang mit dem Schreiben.

(e) Mazzino Montinari, der Herausgeber der kritischen Gesamtausgabe, forderte die Nietzscheforschung dazu auf, philosophische und philologische Methoden zu verbinden. ${ }^{22}$ Montinari hat seine Methode in einigen Artikeln angewendet und nannte sie «die spröde Art, Nietzsche zu lesen». ${ }^{23}$ Er interpretierte Schreibverfahren, Lektüre und Philosophie Nietzsches wechselseitig. Dies erwies sich als besonders ergiebig, weil Nietzsche sich mit der Prozessualität und Materialität des Schreibens intensiv auseinandergesetzt hat. Die Bedingung, philologische und philosophische Ansprüche zusammenzuführen, ist die Fokussierung auf den Text. ${ }^{24}$ Deswegen behandelt diese Dissertation die einbezogenen Manuskripte grösstenteils im Kontext des publizierten Wanderers. Montinari nannte die für Nietzsches Werke bedeutsamen Materialien wie Lesespuren, Lektürenachweise und Exzerpte den «Extratext»: So war er etwa der Ansicht, dass Nietzsches Lektüre «in den Text» gehöre, aber gleichzeitig «über den Text hinaus» weise. ${ }^{25}$ Während Montinari mit dem «Extratext» auf literarische Zeugnisse fokussierte, sollen für die Analyse des Wanderers auch Alltagspraktiken, die Landschaft oder das Schreibverfahren miteinbezogen

18 Vgl. dazu Kittler 2003 [1985], S. 231-242; Kittler 1986; Stingelin 1988; Fietz 1992; Eberwein 2005; Braun 2007; Balke 2011.

19 Vgl. Kittler 2013b.

20 Windgätter 2004, S. 7.

21 Vgl. Günzel/Schmidt-Grépály (Hg.) 2003.

22 Montinari 1982, S. 4.

23 Montinari 1988b, S. 481. Vgl. weiterführend zu Montinaris Methode der Nietzsche-Lektüre: Montinari 1982; D'Iorio 1992.

24 Vgl. Montinari 1987. Man kann Schreibprozesse auch ohne Bezug auf ein publiziertes Werk thematisieren (vgl. Benne 2015a, S. 616-633).

25 Montinari 1988a, S. 137. Vgl. auch Pestalozzi 1991, S. VIII: «Daß Nietzsche auf verschiedensten Wissensgebieten ein unermüdlicher Leser war, ist die Entdeckung, die Montinari mit großem Erfolg zur Geltung brachte und mit der er der Nietzsche-Forschung ein neues Feld erschloß.» 
werden. Das verlangt neben philologischem und historischem auch ein kulturwissenschaftliches Gespür.

\subsubsection{Forschungsstand}

Zur Thematik des Schreibens bei Nietzsche gibt es zahlreiche Publikationen aus unterschiedlichen Disziplinen und mit verschiedenen Interessen (a). Geringer fällt die Anzahl spezifischer Publikationen zum Wanderer aus (b).

(a) Am häufigsten wird Nietzsches Schreiben im Kontext der eben erwähnten medientheoretischen Nietzscheforschung und der Editionsarbeiten thematisiert. Mit der neunten Abteilung der KGW wurde für das Spätwerk eine Grundlage geschaffen, die Nietzsches Schreibarbeit in komplexer Weise nachvollziehen lässt. Für die Forschung an Nietzsches Manuskripten gibt es mittlerweile zahlreiche Hilfsmittel: Die Nachberichte, Kommentare, Nachworte und sonstigen Paratexte der mittlerweile vielen Editionen bilden wichtige Quellen für die Arbeit mit Nietzsches Manuskripten. Für einen philologischen Umgang mit Nietzsches Texten ist die jeweilige Publikationsgeschichte sowie die Geschichte der Nietzsche-Editionen unverzichtbar. ${ }^{26}$ Da Nietzsches Philosophie, Schreibstil und Werkpolitik philologisch geprägt sind, muss sein gut aufgearbeitetes Verhältnis zur Philologie einbezogen werden. ${ }^{27}$ Ebenso wichtig sind die durch Montinaris Editionsarbeiten gewonnenen Erkenntnisse zu Nietzsches Lektüre und Bibliothek. ${ }^{28}$ Neuere Einzelstudien haben u.a. Nietzsches englische, französische und naturwissenschaftliche Lektüre erforscht. ${ }^{29}$

Aufgrund der editorischen Infrastruktur und philologischen Sensibilisierung der Nietzscheforschung entstanden detaillierte Untersuchungen, welche direkt an den Arbeitsmaterialien von Nietzsches Schriften durchgeführt wurden. ${ }^{30}$ So hat Beat Röllin in der Buchreihe «Zur Genealogie des Schreibens» erstmals einen Einblick in die ebenso philosophisch wie werkpolitisch relevanten Werkpläne von 1885 gegeben. ${ }^{31}$ In einer weiteren Studie zeigte Röllin am Druckmanuskript von Jenseits von Gut und Böse exemplarisch auf, welche Kontingenzen in der Buchproduktion auftreten können. ${ }^{32}$ Das mit neun

26 Vgl. Eichberg 2009; Schaberg 2002.

27 Vgl. Cancik 2000; Benne 2005; Blondel 2006; Benne/Santini 2013; Dehrmann 2015.

28 Vgl. die Edition von Nietzsches Bibliothek: Campioni u.a. (Hg.) 2003 bzw. BN. Für ein Verzeichnis von Nietzsches Basler Bibliotheksausleihen, vgl. Crescenzi 1994.

29 Vgl. Brobjer 2008a; Campioni 2009; Moore/Brobjer (Hg.) 2004.

$30 \quad$ Mit Nietzsches Notizen und seinem Exzerpier-Stil setzte sich Thüring 2008 gewinnbringend auseinander; mit Schriftbildern in den Manuskripten und in der Drucktypografie Eichberg 2009, v.a. S. 52-58, Groddeck 2012 und Rahn 2015.

31 Röllin 2012.

32 Röllin 2013. 
Hauptstücken publizierte Jenseits von Gut und Böse hatte ursprünglich deren zehn. Eines davon, das den Titel «Masken» trug, wurde im letzten Moment auf die übrigen Hauptstücke verteilt:

\begin{abstract}
Die Rekonstruktion der rund viermonatigen Entstehungsgeschichte vonJGB von der vermeintlichen Fertigstellung des Manuskripts am 10. April bis zur Auslieferung des Buches am 4. August zeigt uns einerseits, wie Nietzsche bis zum letzten Moment an seinem Text feilte. Sie zeigt uns andererseits, dass sich die endgültige Gestalt von JGB bei allen werkkompositorischen Bemühungen Nietzsches mitunter auch mehr oder weniger kontingenten Umständen verdankt. ${ }^{33}$
\end{abstract}

Die Einsicht, dass Nietzsches Arbeitsweise durchaus Kontingenzen für das publizierte Werk zeitigte, problematisiert den unhinterfragten Zugriff auf dasselbe sowie den Anspruch auf die intentio auctoris oder die «letzte Hand». Zudem entstehen andere Fragestellungen und Interpretationen, welche auch werkpolitische und manuskriptkulturelle Faktoren einbeziehen können.

(b) Zu Menschliches, zum mittleren Nietzsche und zum Motiv des Wanderns gibt es viele philosophische Publikationen. ${ }^{34}$ Die meisten dieser Arbeiten beschäftigen sich jedoch mit dem Wanderer nur als Anhang und im Kontext von Nietzsches freigeistiger Phase. Selbst dort, wo Autoren laut Titel und Ankündigung den Wanderer im Besonderen untersuchen, werden die Belege im besten Fall aus der zweiten Hälfte der $1870 e r$ Jahre genommen, als ob die in dieser Zeit entstandenen Manuskripte und Publikationen ein homogenes Denken repräsentieren. Ein typischer Fall ist Jeremy Fortiers Studie zum Wanderer: Obwohl Fortier die Publikationsgeschichte kennt, deutet er den Wanderer entgegen seiner Ankündigung als Buch über den Freigeist und damit als Anhang zu Menschliches. ${ }^{35}$

Nützlich und fundiert für eine literaturwissenschaftliche wie philosophische Analyse sind die Arbeiten von Vivetta Vivarelli, Marco Brusotti und Olivier Ponton zum mittleren Nietzsche. ${ }^{36} \mathrm{Ihr}$ Augenmerk bei der Aufarbeitung von Nietzsches Beschäftigung mit Montaigne, Pascal und Sterne lag immer auch auf dem Schreibstil und den Schreibreflexionen. Ebenfalls erwähnenswert ist

\footnotetext{
33 Röllin 2013, S. 60.

34 Vgl. Schoeck 1948; Greiner 1972; Heller 1972; Thorgeirsdottir 1996; Riedel 1998; Claesges 1999; Abbey 2000; Chaves 2004; D’Iorio/Ponton (Hg.) 2004; Barros 2007; Cohen 2010; Franco 2011; Fornari 2012; Schestag 2008; Denat/Wotling (Hg.) 2017. Zum Motiv des Wanderns vgl. besonders Campioni 1987; Zittel 1996; Denat 2017.

35 Fortier 2016

36 Vivarelli 1998; Brusotti 1997; Ponton 2001, 2007.
} 
eine Studie zu Landschaft und Stil bei Nietzsche von Lukas Labhart. ${ }^{37}$ Obwohl er sich vor allem für Nietzsches Sprache interessiert und sich weitgehend «allegorisch» auf Landschaften bezieht, enthält seine Dissertation eine wichtige Zitationsauswahl, welche auf die wechselseitigen Beziehungen zwischen Schreibsituation und Philosophie hinweist. Während Labhart die innerliterarischen Zusammenhänge von Landschaft, Individualität und Stil analysiert, soll in der vorliegenden Dissertation gezeigt werden, dass im Falle der St. Moritzer Schreibsituation die inner- und ausserliterarischen Bezüge untrennbar ineinander verschränkt sind. ${ }^{38}$

Gegenüber der Fülle an Arbeiten zu Menschliches fallen die ausschliesslich dem Wanderer gewidmeten Publikationen gering aus. Es sind zunächst hauptsächlich kurze Arbeiten im Kontext des erwähnten HyperNietzschePilotprojekts, in dem die Wanderer-Manuskripte digitalisiert und transkribiert wurden. So hat Inga Gerike die Wanderer-Manuskripte im Rahmen der HyperNietzsche-Edition ediert und untersucht, während Matteo d'Alfonso und Harald Saller die digitalen Editionsmöglichkeiten von HyperNietzsche anhand des Druckmanuskripts vom Wanderer beschreiben. ${ }^{39}$ Diese Aufsätze befassen sich nur knapp mit der Genese vom Wanderer. Es geht vielmehr um die Frage, inwiefern mit digitalen Editionen die Manuskripte einer Textgenese genetisch ediert, codiert sowie einer Forschungsgemeinschaft zur weiteren Bearbeitung zur Verfügung gestellt werden können. Darüber hinaus gibt es einige Aufsätze und kurze Studien zu einzelnen Aphorismen. ${ }^{40}$ Erhellend ist besonders Luca Lupos Beitrag über den Rahmendialog vom Wanderer, der einige der vielen Intertextualitäten und Referenzen dieses vielschichtigen Dialogs genauer untersucht hat. ${ }^{41}$ Zudem widmen zwei Monographien der amerikanischen Nietzscheforschung dem Wanderer eine eigene Lektüre. ${ }^{42}$ Ansonsten gilt: Der Wanderer fristet ein Schattendasein.

37 Vgl. Labhart 2006. Die durch lange Zitationen und Fussnoten geprägte Studie bedient sich mehrheitlich eines nietzscheanischen Vokabulars und lässt materiale und historische Kontexte philosophischen Arbeitens ausser Acht.

38 Labhart interessiert sich für das «literarische[] Phänomen Nietzsche» sowie für sein «literarisch-poetische[s] Programm» (ebd., S. 9 und 8).

39 Vgl. Gerike 2002; d'Alfonso/Saller 2007; D'Iorio 2017.

40 Vgl. Gerhardt 1983; Brusotti 2004; Chaves 2004; Lupo 2014; Fornari 2012; Busellato/ Campioni 2013; Patton 2014; Brücker 2016; Fortier 2016.

41 Lupo 2004. Vgl. für eine kommunikationstheoretische Interpretation Stegmaier 2012, S. 103-105 sowie Zittel 2016, der den Wanderer in seine Studie über die Gattungseigenschaften von Nietzsches Dialogen einbezieht.

42 Vgl. Detwiler 1990. Julian Young widmet den Vermischten Meinungen und dem Wanderer ein eigenes, überzeugendes Kapitel, vgl. Young 2010, S. 273-295. 


\subsubsection{Editionen und Manuskripte}

Die Analyse von Manuskripten, Schreibverfahren und Drucklegungen erfordert einige Vorsichtsmassnahmen im Umgang mit Editionen und Manuskripten: Zunächst ist die Arbeit mit nachgelassenen Manuskripten auf Editionen und deren Kriterien angewiesen. ${ }^{43}$ Selbst wenn ein Zugang zu primären Quellen gegeben ist, stammt das Fachwissen für den Umgang mit Manuskripten und ihrer Materialität sowie die Bestimmungen von Datierungen, Transkriptionen und Vorstufen aus der Editionsarbeit. Mit Ausnahme weniger Nietzscheforscher (meistens Editionsmitarbeitende) kann fast niemand Nietzsches Handschrift der mittleren und späten Phase entziffern. Zudem geht selbst in einer diplomatischen Umschrift der materiale Kontext der Schriftträger, Handschrift, Schriftgrösse, Schreibzeuge etc. verloren. Bereits August Horneffer wünschte sich, dass man zum Nachvollzug von Nietzsches Nachlass ein Heft in seiner «tagebuchartigen Ordnungslosigkeit» herausgeben würde. ${ }^{44}$ Die Untersuchung von nachgelassenen Handschriften ist daher eng verwoben mit ihren Editionen. Wolfram Groddeck und Michael Kohlenbach haben die «lektüreund interpretationssteuernde[n] Weichen» der Kritischen Gesamtausgabe der Werke (KGW) analysiert, wobei betont werden muss, dass sich die Herausgeber dieser Probleme durchaus bewusst waren. ${ }^{45}$

Folgende Probleme und Eigenheiten der Nietzsche-Edition sind für die Wanderer-Manuskripte relevant: (a) die Einteilung in Vorstufen und Fragmente, (b) die Klassifizierung in philosophische Notate und Gelegenheitsnotizen (c) der Textstatus gedruckter Aufzeichnungen, (d) der Vorrang des Denkens vor dem Schreiben, (e) der mechanische Rückgriff auf Schreibprozesse und (f) der Nachlass als Lückenbüsser allfälliger Ambivalenzen.

(a) Nietzsches Nachlass wird grösstenteils in «nachgelassene Fragmente» und sogenannte Vorstufen unterteilt. Vorstufen sind Wort-, Satz- oder Texteinheiten, die als Übergangsstufe zu einem publizierten Text interpretiert wurden. Fragmente wiederum sind Wort-, Satz- oder Texteinheiten, die keine direkte Verbindung zu einem publizierten Text aufweisen. Während erstere in den Nachberichten der KGW als Verweise aufgeführt sind, können letztere als rezipierbare und nummerierte Fragmentreihen gelesen werden. Der fertige Text dient demnach als entscheidendes Kriterium, von dem aus die Manuskripte klassifiziert werden.

43 Vgl. Reuß 1999, S. 1-25; Benne 2013, S. 7; Grésillon 1999, S. 157-163.

44 Horneffer 1907, S. 649. Zudem forderte er, dass man die nachgelassenen Manuskripte so herausgeben sollte, wie sie vorgefunden wurden, vgl. Horneffer 1906, S. 85 f.

45 Groddeck/Kohlenbach 1995, S. 27. Vgl. auch Montinari 1988a; Groddeck 1991; Röllin/ Stockmar 2007 . 
〈Fragment〉 wäre demnach nur eine interpretatorische Negativ-Bestimmung: Was sich nicht als 〈Vorstufe〉 zuordnen läßt, ist ein selbständiger 〈Fragmenttext>. In der Tat sind die Herausgeber der KGW auch so verfahren: sie haben 〈Fragmente〉, die sich irgendwie als «Vorstufen zuordnen ließen, oft - aber nicht immer - zur Veröffentlichung in den Nachberichten zurückgehalten, [....$^{46}$

Oft gibt es auch von den Vorstufen und den nicht verwendeten Notizen mehrere Versionen, unsichere Lesarten oder Abkürzungen, weshalb ein Text (bzw. ein nachgelassenes Fragment) erst hergestellt werden musste. Zudem unterstellt diese Einteilung den offenen Schreibprozessen eine teleologische Ausrichtung auf Texte, Werke oder sonstige Verwertungsmöglichkeiten. ${ }^{47}$ Auf diese Weise werden die Notate aus dem materialen Kontext der Schriftträger herausgelöst und als eigenständige Texte rezipierbar gemacht. Groddeck und Kohlenbach schlagen deshalb vor, anstatt von Fragmenten von «Aufzeichnungen» zu sprechen. ${ }^{48}$ Das Problem ist längst erkannt, weshalb die neunte Abteilung der KGW auf die Unterscheidung von Vorstufen und Fragmenten verzichtet.

(b) Innerhalb der nicht als Vorstufen klassifizierten Aufzeichnungen gibt es eine weitere Unterscheidung in abgedruckte philosophische Fragmente und so genannte Gelegenheitsnotizen. Aufzeichnungen wie «Briefentwürfe und -dispositionen, Notizen und Bemerkungen von äußerlichem und zufälligem Inhalt, z.B. Andeutungen finanzieller Fragen, Berechnungen, Notizen über Preise, Reisen, Spazierwege, Besuche und dergleichen» werden nicht abgedruckt, sondern nur im Apparat indexiert. ${ }^{49}$ Es finden sich in den Notizbüchern N IV 1-5 neben philosophischen Notaten auch Adressen, Tagesabläufe, Wochenpläne, To-Do-Listen, Besorgungslisten, Briefskizzen, Wegbeschreibungen, numerische Berechnungen, persönliche Erinnerungen und vieles mehr. Als solche sind die Notizbücher zugleich Träger alltäglicher Bedürfnisse und Arbeitsinstrumente für den Wanderer. Die Sortierung und Selektion der KGW bietet bei aller Sorgfalt eine Textlektüre an, die auf diese Weise in den Notizbüchern und Arbeitsheften nie gegeben war. Nietzsches Notizen sind keine unveröffentlichten Texte, sondern Arbeitsmanuskripte im Kontext einer mo-

$46 \quad$ Groddeck 1991, S. 169.

47 Ebd., S. 173: «Die Schreibbewegung ist nicht einsinnig auf ein Ziel ausgerichtet [...], sondern ist ebensosehr flächig zu denken: die einzelnen Notate treten in neue Konstellationen, in einem Prozeß von Relektüre und Neuformulierung verschwinden sie und tauchen oft unvermittelt wieder auf.» Vgl. auch Hoffmann 2008b, S. 208f.: Schreiben dürfe, so Hoffmann, nicht mit der Produktion von Texten verwechselt werden, weil nicht alle Schreibprozesse zu Texten führen.

48 Groddeck/Kohlenbach 1995, S. 34.

$49 \quad \mathrm{KGW}$ IV 4, S. 4. 
bilen Schreibsituation und eines persönlichen Alltags. ${ }^{50}$ Für die Analyse der Schreibsituation sind Gelegenheitsnotizen deshalb relevant. Dies versuche ich besonders im Kapitel zur Diätetik (Kap. 3.3) eingehend darzulegen.

(c) Notate und sonstige Aufzeichnungen sind keine fortlaufend lesbaren Texte. Handschriftliche Notate sträuben sich gegen «das Gesetz der linearen Sukzession», das für alle lesbaren und gedruckten Texte gilt. ${ }^{51}$ Die Übertragung von Nietzsches Manuskripten in den gedruckten Text führt zu einem «Druckbild, das weit mehr an publizierte Werke erinnert, als daß es den ausgeprägten Notat- und Entwurfscharakter von Nietzsches Manuskripten verriete.» ${ }^{52}$ Das lässt sich aus der Praxis nur bestätigen: Hat man einmal mit Nietzsches Notizbüchern gearbeitet, wirken sie im wohlgeordneten Druckbild viel zu klar, zu eindeutig, zu lesbar und zu gehaltvoll. Dieser suggerierte Textstatus der flüchtigen Notizen lässt sich auch durch die aufwendigen Nachberichte der KGW nicht auflösen: «Was wir in den Textbänden einer Ausgabe zu lesen bekommen, scheint allein deswegen einem anderen Dignitätsniveau der Schriftlichkeit zuzugehören, weil es den Charakter eines ultimativen, und deswegen auch umstandslos zitierfähigen Resultats ausstrahlt, demgegenüber im Apparat allenfalls Prozeduren der Vorläufigkeit Erwähnung finden.» ${ }^{53}$ Deshalb sind die Wanderer-Manuskripte nur durch Archivzugang oder Faksimiles erforschbar.

(d) Der Fokus auf Manuskripte führt nicht selten wieder zum problematischen Vorrang des Denkens vor dem Schreiben. In der englischen Werkausgabe von 2012 werden beispielsweise die Notizbücher des mittleren Nietzsches als Suche nach der adäquaten Form seiner Gedanken beschrieben: «one sees in these notebooks Nietzsche's ongoing struggle as writer to find an adequate form for expression of his consciously idiosyncratic way of philosophical thought.» ${ }^{54}$ Die Formulierung suggeriert einen Denker, der verzweifelt nach der adäquaten Form für seine Gedanken sucht. Dieses Urteil ist ganz nahe am Schreibverständnis von Julius Kaftan, der schon 1906 einen Aufsatz mit dem

5o Vgl. dazu Stingelin/Thiele 2010, S. 18f. Vgl. auch Hoffmann 2008c, S. 45: «Sie [die Hefte Musils] sind nicht Ergebnis von (Zeit)bearbeitung, sondern Arbeitsstätte, verhalten sich zur Schreibtätigkeit des Dichters wie dessen Werkbank.»

51 Reuß 1999, S. 16. Vgl. für dasselbe Problem in anderen Editionen Radecke 2014; Kondrup 2003.

52 Röllin/Stockmar 2007, S. 23.

53 Groddeck/Kohlenbach 1995, S. 27.

54 Handwerk 2012, S. 583 . Bereits Koegel beschrieb 1896 «Friedrich Nietzsches Arbeitsweise» mit der Sprache der Genieästhetik: «Die zurückgestaute Schaffenskraft entladet sich mit leidenschaftlichem Ungestüm und steigert sich bisweilen zu fast visionär verzückter Inspiration.» (Koegel in GAK, Bd. 9, S. XVf.) Vgl. auch Horneffer 1906, S. 9o: «Wie er Teile eines nebelhaften Gedankengebäudes mit größter Genauigkeit schaute, gab er sie auch mit höchster Klarheit und Eindringlichkeit wieder.» 
Titel «Aus der Werkstatt des Übermenschen» schrieb. Unter Werkstatt verstand Kaftan das geistige «System» Nietzsches, welches er aufgrund der unvollkommenen Notizen- und Aphorismenform rekonstruieren wollte. ${ }^{55}$ Kaftan unterstellt durch seine Rekonstruktion, dass Nietzsche es versäumt hat, seine Gedanken klar zu kommunizieren. Selbst bei den Forschungsarbeiten zu Nietzsches Stil finden sich zahlreiche weitere Beispiele: So etwa bei Alexander Nehamas, wenn er behauptet, Nietzsches Perspektivismus führe zu einem Stilpluralismus. ${ }^{56}$ Oder wenn bei Werner Stegmaier trotz vieler Gedanken über die Form von der «Kommunikation seines Philosophierens» gesprochen wird, als ob sich bei Nietzsche das geistige Denken unabhängig von den Kommunikationsformen vollziehe. ${ }^{57}$ Ebenso skeptisch bin ich gegenüber der Aussage, Nietzsche «arbeitete seinen Text zum Notenblatt um», oder er philosophiere musikalisch, tänzerisch uvm. ${ }^{58}$ Es schielt hier immer noch der unabhängige Autor hervor, der sich seine Formen autonom auswählt (letztendlich der Genie-Gedanke). Der Stil wird auf diese Weise dem Primat des Denkens einmal mehr unterstellt.

(e) Die Zugänglichkeit von Manuskripten verführt zur philologischen Illustration philosophischer Interpretationen. Mit den heutigen Ressourcen der Nietzscheforschung (analoge kritische und digitale genetische Edition, Nachberichte, Kommentare, Autorenbibliothek, Handbücher, Fachzeitschriften etc.) ist Vorsicht geboten, nicht einem «Big Data»-Zwang zu verfallen und alle Informationen nur aufgrund ihrer Existenz in eine Argumentation einzubauen. Es ist weder wünschenswert noch philosophisch ergiebig, wenn eines guten Tons wegen jede philosophische Aussage durch Nachlassstellen belegt wird. Zudem ist der kommentierte Stufenapparat eines Gedanken noch keine Erklärung desselben. ${ }^{59}$ Es ist in Zukunft verstärkt eine abwägende Verhältnismässigkeit geboten, welche den Einbezug zusätzlicher Materialien mit dem philosophischen Anliegen verbindet. Es muss nicht jedes Nachlassmaterial, jeder Entwurf, jedes Notizbuch aus Prinzip konsultiert werden. Dies gilt bereits für ein vergleichsweise kleines Werk, wie der Wanderer eines ist: «Ein komplettes dossier génétique dieses kleinen Werks allein würde leicht etwa 1000

$55 \quad$ Kaftan 1906, S. 8.

56 Vgl. Nehamas 2012, S. 20.

57 Stegmaier 2013, S. 98. Vgl. auch Zittel 2016, S. 98, der den Rahmendialog vom Wanderer als Versuch einer «adäquate[n] Ausdrucksform» für Nietzsches «Sprach- und Erkenntnisskepsis» interpretiert.

58 Schlaffer 2007, S. 30.

59 Diese fragwürdige Methode findet sich bei Richard Perkins, der ausgehend von seinem kommentierten Stufenapparat eines Aphorismus eine systematische und damit vollständige Bedeutungsanalyse vorzunehmen glaubt, vgl. Perkins 1977. 
faksimilierte Seiten umfassen, hinzu käme dieselbe Menge an diplomatischer Transkription sowie ein kritischer Apparat. Eine zusätzliche Darstellung der Genese würde nochmals ca. 1000 Seiten addieren.» ${ }^{60}$ Selbst wenn es möglich wäre, würde dies ein «halbes Forscherleben» in Anspruch nehmen, weshalb man nicht umhin kommt, gezielte und selektive Fragen an ein genetisches Dossier zu stellen. Zudem möchte ich mit der vorliegenden Dissertation zeigen, dass Manuskripte nur einen Teil der Werkgenese ausmachen. Um Nietzsches Wanderer-Manuskripte formiert sich eine Schreibsituation, die von der Landschaft bis zur Diät aktiv am Schreiben teilhat.

(f) Die Systematisierung wie auch die Widersprüchlichkeit von Nietzsches Philosophie wird oft durch die Missachtung der Materialzusammengehörigkeit, Werkphasen oder Textgenese ermöglicht. ${ }^{61}$ Trotzdem sollte der Einbezug von Manuskripten nicht primär dazu dienen, Ambivalenzen und Probleme in Nietzsches Werken zu glätten. Die komplexen Wanderer-Manuskripte zeigen durchaus Ambivalenzen, weshalb der in der Nietzscheforschung verbreiteten Haltung, die Paradoxien entstünden bloss durch fehlende Kontextualisierung, widersprochen werden muss: «Seine [Nietzsches] Schriften werden dann ambivalent oder widersprüchlich, wenn seine Begriffe aus ihren jeweiligen Kontexten gelöst und über sie hinweg verallgemeinert werden.» ${ }^{62}$ Die Unterscheidung von Werkphasen, Produktionsbedingungen und Manuskripten führt nicht teleologisch zu mehr Klarheit und Systematik. Durch die Fokussierung auf den Sommer 1879 versuche ich eine Vorstellung des philosophischen Arbeitens zu vermitteln, welche die vielen Veränderungen und Dynamiken eines schreibenden Denkens einbezieht. So sind beispielsweise die intensiv überarbeiteten Aphorismen den wenig überarbeiteten gegenüberzustellen, was in der Folge nicht das Bild eines akribisch korrigierenden und abschleifenden Schriftstellers bestätigt. Ähnlich verhält es sich mit der Untersuchung von Nietzsches Lesespuren, die vielerorts zeigen, dass Nietzsche andere Autoren nicht immer mit philologischer Genauigkeit und Langsamkeit gelesen hat. ${ }^{63}$

\footnotetext{
$60 \quad$ Benne 2005, S. 350, Fussnote 525.

61 Vgl. D'Iorio/Ponton 2004, S. 6.

62 Stegmaier 2012, S. 71.

63 Vgl. beispielsweise Heit 2013, der ausgehend von Nietzsches Kritik an plündernden Lesern, auf Nietzsches eigene plündernde Lektüre hinweist.
} 
Eine publikationsgeschichtlich wie werkpolitisch relevante Frage betrifft die Eigenständigkeit vom Wanderer. Bekanntlich werden die Vermischten Meinungen und der Wanderer als Menschliches, Allzumenschliches II zusammengefasst. Ist der Wanderer ein zweiter Anhang von Menschliches oder ein eigenständiges philosophisches Buch? Das ist entgegen der Einschätzung einiger Interpreten alles andere als klar. ${ }^{64}$ Für beide Positionen gibt es Argumente, wobei vieles für einen autonomeren Status vom Wanderer spricht. Die philologische wie philosophische Zugehörigkeit differiert deshalb je nach Kriterium.

\subsubsection{Eigenständige Philosophie vs. freigeistige Phase}

Nur selten wurde der Wanderer separat und eigenständig gelesen. Selbst Detailstudien mit sorgfältiger Unterscheidung verschiedener Werkphasen entging die Spezifität und Ausnahmestellung dieses Buches. So werden beispielsweise in den lesenswerten Quellenstudien von Aldo Venturelli die vielen Textstellen zur Diätetik auf den im Wanderer kaum vorkommenden Freigeist bezogen. ${ }^{65}$ Der Hauptgrund dafür ist das von Nietzsche selbst eingeführte Narrativ einer freigeistigen Phase, das zunächst im Klappentext der Fröhlichen Wissenschaft und dann in den Vorworten der neuen Werkausgabe von 1886 erschien (Abb. 1).

Die Hinweise eines eigenständigen Status des Wanderers liegen indessen schon seit langem vor: So konstatiert Karl Jaspers, «daß mit Nietzsche seit 1880 eine so tiefgreifende Veränderung vor sich geht wie niemals vorher in seinem Leben.» ${ }^{66}$ Dem fügt Curt Paul Janz präzisierend hinzu, dass «1879/1880» ein «weitausgreifender Umbruch» geschehe. ${ }^{67}$ Jaspers wie Janz führen jedoch seelische und körperliche Leiden als Gründe für Nietzsches Veränderung ins Feld. Demgegenüber verfolgt die vorliegende Arbeit eine philosophische Perspektive. Bruce Detwiler, der eine Lektüre vom Wanderer in Bezug auf Demokratie wagte, bemerkt scharfsinnig: «A careful reading of The Wanderer and His Shadow, however, suggests that in that book the tenor of the whole is anomalous. Throughout, the orientation is cooler, more consciously rational, and more

64 Vgl. etwa die Behauptung in den Endnoten von Franco 2011, S. 233 f.

65 Vgl. Venturelli 2003, S. 147f.: «Das Motto des freien Geistes - <Frieden um mich und ein Wohlgefallen an allen nächsten Dingen - erinnert so an die Hirten der EvangelistenErzählungen [...].»

66 Jaspers 2010, S. 94.

67 Janz 1978, S. 12-14, hier S. 12. Janz sieht den Wanderer auch eher der Morgenröte als Menschliches zugehörig (ebd., S. 17). 
Mit diesem Buche kommt eine Reihe von Schriften FRIEDRICH NIETZSCHE's zum Abschluss, deren gemeinsames Ziel ist, ein neues Bild und Ideal des Freigeistes aufzustellen. In diese Reihe gehören:

Menschliches, Allzumenschliches. Mit Anhang: Vermischte Meinüngen und Sprüche.

Der Wanderer und sein Schatten.

Morgenröthe. Gedanken über die moralischen Vorurtheile.

\section{Die fröhliche Wissenschaft.}

Abb. 1 Klappentext auf dem Buchumschlag der Erstausgabe der Fröhlichen Wissenschaft von 1882

pacific than that of the other periods.» ${ }^{68}$ Dies heisst nicht, dass sich im Wanderer alles grundlegend ändert. ${ }^{69}$ Es soll aber in den folgenden Kapiteln gezeigt werden, dass sich der Wanderer in wesentlichen Punkten von Menschliches und den Vermischten Meinungen unterscheidet. So hat erstens Nietzsches veränderte Haltung zur Autorschaft ebenso philosophische wie praktische Konsequenzen gezeitigt. Zweitens ist der Wanderer in einem lockeren Stil gehalten, der sich nicht mehr an der knappen und abgeschliffenen Sentenzenkunst der französischen Moralisten orientiert. Drittens entwickelt Nietzsche im Wanderer eine Lehre der «nächsten Dinge» und viertens zeichnet sich der Wanderer

68 Detwiler 1990, S. 178.

69 Viele Passagen zur Moral und zum freien Willen (vgl. WS 11, KSA 2, S. $546 f$.; WS 12, KSA 2, S. 547 f.; WS 61, KSA 2, S. 580 ; WS 68, KSA 2, S. 582 ) weichen kaum von Menschliches ab (vgl. MA 18, KSA 2, S. 38-40; MA 39, KSA 2, S. 62-64; MA 99, KSA 2, S. 95f.; MA 102, KSA 2, S. 99). Wenn es beispielsweise im Wanderer heisst, dass der Glaube an den freien Willen voraussetze, dass «jede einzelne Handlung isoliert und untheilbar» sei (WS 11, KSA 2, S. 546), dann klingt das wie in Menschliches: «ja jetzt noch meinen wir im Grunde, alle Empfindungen und Handlungen seien Acte des freien Willens; wenn das fühlende Individuum sich selbst betrachtet, so hält es jede Empfindung, jede Veränderung für etwas I s o lir t e s, das heisst Unbedingtes, Zusammenhangloses» (MA 18, KSA 2, S. 39f.). 
durch eine bemerkenswert demokratiefreundliche Haltung aus. Da es sich um vier zentrale philosophische Inhalte handelt, muss in Frage gestellt werden, inwiefern man den Wanderer als selbstverständlichen Teil der «freigeistigen Phase» Nietzsches verstehen kann und ob für Nietzsches Arbeitsweise eine solche Einteilung in Phasen Sinn macht.

\subsubsection{Eigenständige Publikation aufgrund des abgrenzbaren Materials}

Die Fokussierung auf die Schreibsituation sowie die mehrheitliche Verwertung von St. Moritzer Notizen sind einzigartig und spezifisch für den Wanderer. Davon zeugt der Arbeitstitel «St. Moritzer Gedanken-Gänge», welcher den Ort, den Zeitraum und die Schreibpraktiken als miteinander verknüpfte Aspekte enthält. ${ }^{70}$

Nietzsche verarbeitete in den zwei ersten Aphorismenbüchern unterschiedliche Manuskripte, die an verschiedenen Orten entstanden sind. Menschliches war aus Diktatniederschriften, weit verstreuten Notizen, teilweise noch aus der Zeit vor dem Bayreuth-Besuch, entstanden. ${ }^{71}$ Zudem waren die frühen Aufzeichnungen - Sorrentiner Papiere genannt - noch im Oktober 1876 als fünfte Unzeitgemässe Betrachtung unter dem Entwurfstitel «Der Freigeist» geplant. ${ }^{72}$ Die Vermischten Meinungen wiederum wurden in Nietzsches letzter Basler Wohnung (Bachlettenstr. 11) fertiggestellt und sind mitunter eine Resteverwertung des Materials von Menschliches. ${ }^{73}$ Nietzsche beschrieb zwischen Mai und November 1878 zehn Notizbücher, wovon ein Teil als Grundlage für die Vermischten Meinungen benutzt wurde. Zwischen November und Mai/Juni sind keine Notizbücher bekannt, was wohl dem schlimmen Gesundheitszustand Nietzsches in dieser Zeit zuzuschreiben ist.

Umso interessanter ist es, dass Nietzsche nach dieser Zäsur für den Wanderer nicht auf die vielen Restnotizen von 1878 und früher zurückgriff. ${ }^{74}$ Er beschrieb im St. Moritzer Sommer 1879 neue Notizbücher, aus denen er sich zur

$70 \quad$ Vgl. M I 2, S. 91 bzw. NL 1879, 43[Titel], KSA 8, S. 610.

71 Vgl. KGW IV 4, S. 102-105.

72 Vgl. ebd. Erst nach dem Sorrentiner Winter und dem vielen hinzugekommenen Material änderten sich die Pläne: «aus der ein en wurden neun 〈Unzeitgemäße〉, die den neun Abschnitten des jetzigen «Menschlichen〉 ungefähr entsprechen.» (Koegel in GAK, Bd. 9, S. XIX) Für eine Aufarbeitung der Sorrent-Reise und der dortigen Schreibarbeiten vgl. D'Iorio 2012.

73 Vgl. KGW IV 4, S. 105 f.

74 Wenn auch nicht von der Hand zu weisen ist, dass frühere Einfälle wiederkehrten. So etwa im Fall von WS 199 (KSA 2, S. 640), einem Kurzaphorismus, der sich als Entwurf ebenso im Grossoktavheft U II 5 (NL 1876, 15[14], KSA 8, S. 282; KGW IV 4, S. 427) wie auch wieder im Notizbuch N IV 1, S. 16 von 1879 findet. 
Erstellung des Wanderers überwiegend bediente. Nietzsche legte mehr Wert auf das Einhalten dieses Schreibverfahrens, als auf ein kohärentes Buch. Der Wanderer war somit das erste Buch, welches in einer abgrenzbaren Schreibsituation erarbeitet wurde.

\subsubsection{Eigenständige Publikation vs. Anhang}

Die Erstpublikation des Wanderers hatte ein eigenständiges Titelblatt. Während Nietzsche die Vermischten Meinungen als «Anhang» von Menschliches publizierte, findet sich beim Wanderer dieser Hinweis nicht mehr auf dem Titelblatt, sondern nur noch kleingedruckt auf dessen Rückseite (Abb. 2, 3 und 4). Zudem ist nicht mehr von einem «Anhang», sondern von einem «Nachtrag» die Rede. Ein «Anhang» ist sekundär auf ein Hauptwerk bezogen und könnte hypothetisch auch gleichzeitig mit letzterem publiziert worden sein. Tatsächlich plante Nietzsche für die Publikation der Vermischten Meinungen fortlaufende Seitenzahlen und Aphorismen-Nummern (was Schmeitzner aber verhinderte) sowie eine Voltaire-Widmung am Buchende, die erst im letzten Moment wegfiel. ${ }^{75}$ Der Ausdruck «Anhang» weckt zudem den Eindruck einer Resteverwertung aus zweitrangigen Inhalten, die es nicht in das Hauptwerk geschafft haben (was für die Vermischten Meinungen teilweise zutrifft). Demgegenüber ist ein «Nachtrag» zeitlich klar versetzt und deutet im philosophischen Kontext verbesserte, revidierte und gereifte Gedanken an. Nietzsche wollte im November 1879 den Wanderer zunächst im selben Titel-Layout wie die Vermischten Meinungen drucken lassen (Abb. 3). Er entschied sich aber für ein eigenständiges Titelblatt und den kleingedruckten Eintrag, womit er seinem neuen Buch einen wenn auch nicht unabhängigen, so doch eigenständigen Charakter verlieh. Dies unterstreicht auch der Titel, welcher in einer auffällig serifenlosen Grotesk-Type gesetzt ist. Das entspricht nicht dem Narrativ einer einheitlichen freigeistigen Phase mit einem Hauptwerk und zwei Anhängen. Und trotzdem kann der Status des Wanderers nicht eindeutig bestimmt werden, weil Nietzsche schon am 18. Dezember 1879, also just nach

75 Der ursprüngliche Schluss der Vermischten Meinungen lautete: «Nennen wir an dieser Stelle noch einmal den Namen Voltaire. Welches wird einmal seine hö ch ste Ehre sein, ihm erwiesen von den freiesten Geistern zukünftiger Geschlechter? Seine 〈letzte Ehre`. - - -» (KGW IV 4, S. 301). Dieser Buchschluss wäre nochmals ein klarer Rückgriff auf die rahmende Voltaire-Widmung von Menschliches gewesen und hätte im Sinne eines Anhanges den Effekt einer Klammerbewegung gehabt. Dieser Passus wurde aber in der letzten Korrekturphase gestrichen und als Schluss der Aphorismus «H a d e sfa hrt» angefügt (vgl. auch Schmeitzner an N., 7·3.1879, Nr. 1157, KGB II 6/2, S. 1045). 
Erhalt des fertigen Wanderers, in seiner Korrespondenz wieder von der «ganze[n] 〈M en schlichkeit 〉 mit den 2 Anhängen» spricht. ${ }^{76}$

Auch in den Folgepublikationen finden sich weitere Hinweise auf die Eigenständigkeit vom Wanderer: Noch in der Morgenröte 1881 und in der Fröhlichen Wissenschaft 1882 erscheint der Wanderer als eigener Titel, während die Vermischten Meinungen als Anhang aufgelistet werden. ${ }^{77}$ Im Nachlass lässt sich kein klares Bild mehr zeichnen, weil Nietzsche mit immer neuen Werkplänen experimentierte und dabei je nach Kontext verschiedene Zuordnungen seiner bisherigen Publikationen vornahm. ${ }^{78}$ Auch materiale Aspekte wie Grösse, Titel oder Anzahl Bände spielen oft die entscheidende Rolle, ob Nietzsche ein Werk separat aufführt, subsumiert oder sogar weglässt. ${ }^{79}$ Es verwundert daher nicht, dass in einem Werkplan aus dem Sommer 1885 («Friedrich Nietzsche, gesammelte Schriften») der Wanderer sogar fehlt. ${ }^{80}$ Aus diesen Hinweisen ergibt sich folgende Einschätzung: Der Wanderer war bis 1885, als Nietzsche eine vollständige Überarbeitung von Menschliches plante, in den Augen des Autors grösstenteils ein eigenständiges Werk. Um die heute selbstverständliche Einordnung vom Wanderer als Nachtrag zu Menschliches zu verstehen, muss der Kontext der Neuen Ausgaben von 1886 rekapituliert werden.

$76 \quad$ N. an Schmeitzner, 18.12.1879, Nr. 915, KGB II 5, S. 471.

77 Vgl. die Umschlagrückseite der Erstausgabe der Morgenröte (1881) sowie den Werbetext der Erstausgabe der Fröhlichen Wissenschaft (1882).

78 Es finden sich beispielsweise im Sommer 1882 im Notizbuch N V 9 (S. 4 und 5) hintereinander zwei Werkpläne: Im ersten Entwurf werden die Vermischten Meinungen nicht einmal wörtlich erwähnt, sondern unter «Menschliches Allzumenschliches. Mit Anhang» subsumiert (NL 1882, 1[13], KSA 10, S. 11). Im zweiten Entwurf unter dem Titel «Die Pflugschar» werden sie wieder als separater Titel angeführt (NL 1882, 1[14], KSA 10, S. 12). So ergibt sich in einem Entwurf eine Gesamtausgabe mit vier, im anderen mit fünf Büchern. Zu Werkplänen bei Nietzsche vgl. Röllin 2012.

79 So übte beispielsweise die biblische «Zehnzahl» eine grosse Anziehungskraft auf Nietzsche aus. Je nach Werkphase und weiteren Publikationen änderte sich dann einfach die Zählweise, um weiterhin auf zehn Bücher zu kommen: «Die Zählweise war freilich nicht immer dieselbe - bereits 1882 rechnete er zehn Bücher zu seinem Werk. «10 Werke», das hiess im Sommer 1886 die sieben erschienenen Werke von $G T$ bis $J G B$ sowie drei <in Vorbereitung befindliche [...]» (Röllin 2012, S. 128).

8o Dies, während die Vermischten Meinungen als eigene Publikation unter dem Titel «Unter uns.) Vermischte Meinungen und Sprüche» aufgeführt sind (NL 1885, 41[1], KSA 11, S. 669). Röllin vermutet, dass der Wanderer nicht in die «schicksalshafte Geschichte» der Selbstinszenierung Nietzsches passte (Röllin 2012, S. 129). 


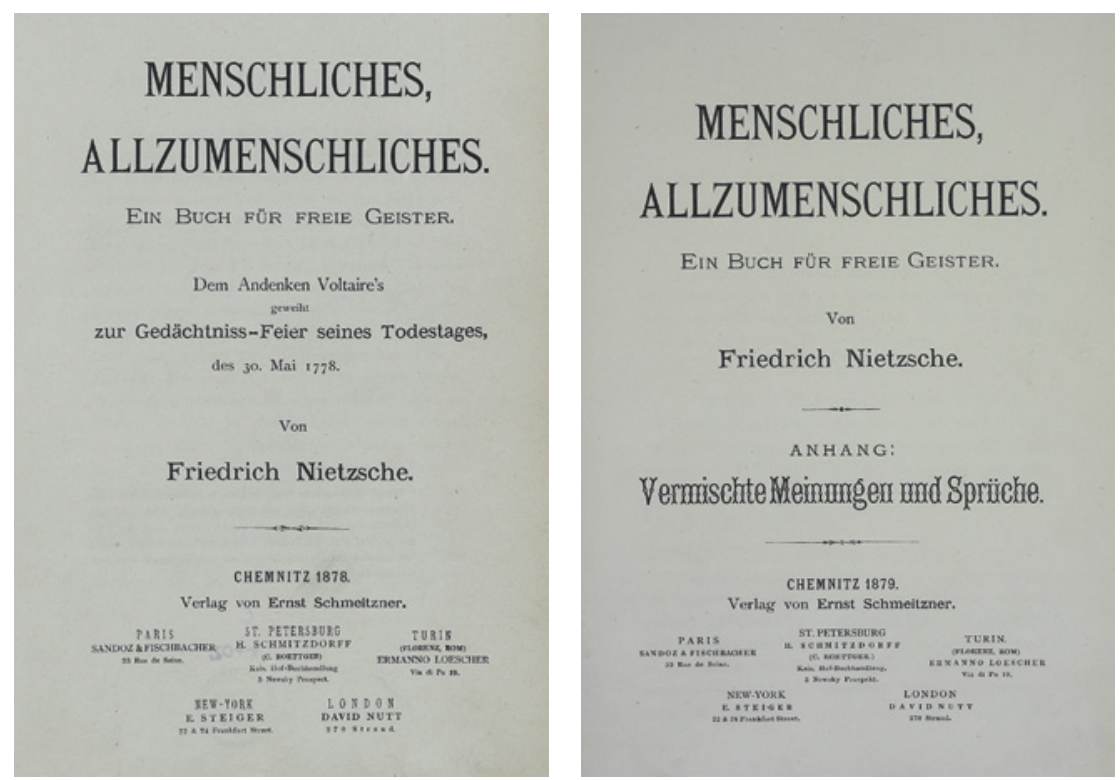

Abb. 2 Titelblätter der Erstausgaben von Menschliches und den Vermischte Meinungen

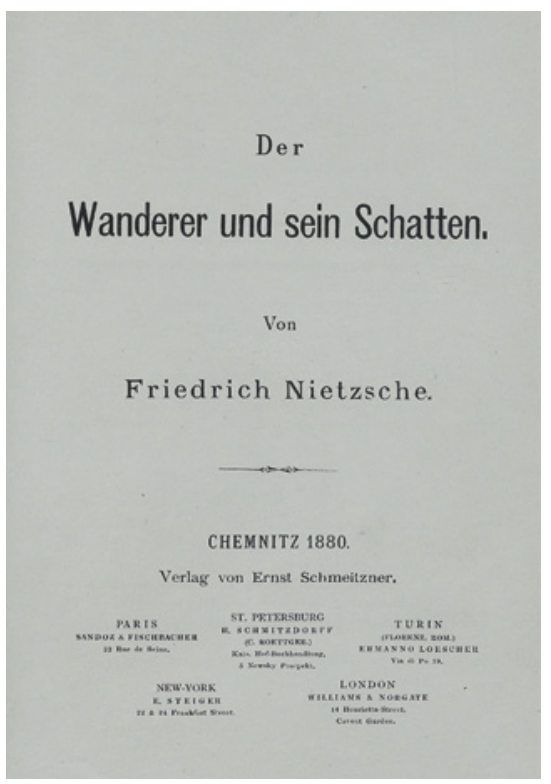

Der

Wanderer und sein Schatten.

Zweiter und Letxter Nachitrag

we do trather

erschienenen Gedankensammlung

Menschliches, Allzmmenschliches

EIN BUCH FÜR FREIE GEISTEP.

Von

Friedrich Nietzsche.

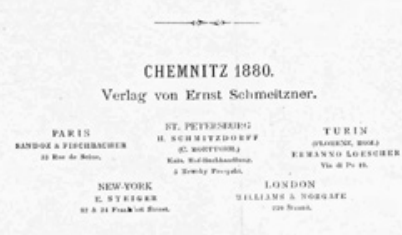

Abb. 3 Titelblatt von der Erstausgabe des Wanderers sowie früherer Entwurf 


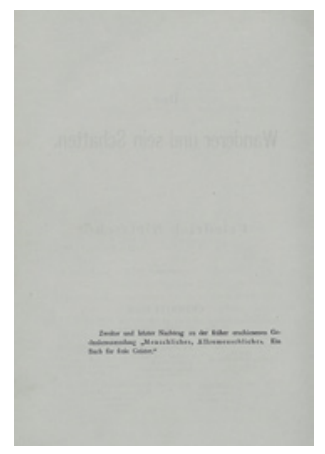

Zweiter und letzter Nachtrag zu der früher erschienenen Gedankensammlung „Menschliches, Allzumenschliches. Ein Buch für freie Geister."

Abb. 4 Kleingedruckter Hinweis auf der Rückseite des Titelblatts der Erstausgabe des Wanderers

\subsubsection{Die Ausgabe von 1886 (Menschliches, Allzumenschliches II)}

Die Idee, die Vermischten Meinungen und den Wanderer in einem Buch als Anhänge zusammenzuführen, stand zwar schon 1879 im Raum, jedoch bezogen auf eine zukünftige Gesamtausgabe. ${ }^{81}$ Erst im Rahmen der 1886 bei Fritzsch veröffentlichten Neuausgaben wurden Menschliches, Vermischte Meinungen und der Wanderer zu einem Doppelband zusammengefügt. ${ }^{82}$ Damit erhielten sie die bis heute bekannte Publikationsform. Diese Zusammenlegung war jedoch nicht nur inhaltlich, sondern auch materiell motiviert: Es blieben von den Erstauflagen der drei Aphorismenbücher nämlich so viele Exemplare übrig, dass die neue Ausgabe mit den Restexemplaren erstellt wurde. ${ }^{83}$ Nietzsche

81 Gast schrieb noch während der Erstellung des Druckmanuskripts vom Wanderer: «Ich dachte so: der jetzt auszudruckende 2te Nachtrag solle mit dem ersten zusammen einen solchen Band ergeben, wie das Hauptbuch selber, demnach circa 220 Druckseiten erhalten. Wieviel das bis jetzt von mir Abgeschriebene ausmachen wird, kann ich nicht sagen: ich dächte etwa 130-40 Seiten.» (Gast an N., 1./2.10.1879, Nr. 1235, KGB II 6/2, S. 1177) Da die Vermischten Meinungen schon separat publiziert wurden und für den Wanderer bereits alles aufgegleist war, kann sich die Bemerkung von Peter Gast nur auf eine zukünftige Gesamtausgabe beziehen. Daran wird im Übrigen ersichtlich, wie früh schon die Idee einer Neuausgabe und deren buchtechnische Gestaltung thematisiert wurden.

82 Die Auslieferung erfolgte am 31. Oktober 1886. Die Titelblätter sind wie folgt aufgebaut: «MENSCHLICHES, / ALLZUMENSCHLICHES. / Ein Buch für freie Geister. / Von / Friedrich Nietzsche / Erster Band / Neue Ausgabe / mit einer einführenden Vorrede / Leipzig, / Verlag von E. W. Fritzsch. / 1886.» und «MENSCHLICHES, / ALLZUMENSCHLICHES. / Ein Buch für freie Geister. / Von / Friedrich Nietzsche / Zweiter Band / Neue Ausgabe / mit einer einführenden Vorrede / Leipzig, / Verlag von E. W. Fritzsch. / 1886.» Im zweiten Band erscheinen die Vermischten Meinungen als «Erste Abtheilung» und der Wanderer als «Zweite Abtheilung». Vgl. dazu auch Schaberg 2002, S. 291.

83 Vgl. Schaberg 2002, S. 175-178. Der Wanderer war bis zum ersten Band von Also sprach Zarathustra das am schlechtesten verkaufte Buch Nietzsches. Im Juli 1886 waren noch 
nutzte diese Neuausgabe, um im Vorwort die Vermischten Meinungen und den Wanderer zu einer einzigen Denkphase mit Menschliches zu verweben: «Die Vermischten Meinungen und Sprüche sind, ebenso wie der Wanderer und sein Schatten, zuerst e in z eln als Fortsetzungen und Anhänge jenes eben genannten menschlich-allzumenschlichen 〈Buchs für freie Geister〉 herausgegeben worden: zugleich als Fortsetzung und Verdoppelung einer geistigen Kur, nämlich der antiromantischen Selbstbehandlung [...].» ${ }^{84}$ Diese retrospektive Umdeutung des Wanderers unterschlägt aber wichtige Veränderungen in Nietzsches Philosophie und Schreibpraktiken sowie den eben erläuterten Publikationskontext. Die neuen Vorreden von 1886 stehen im Kontext einer Werkausgabe, welche werkpolitische Strategien verfolgt. Es wäre zu analysieren, inwiefern Werkausgaben - erst Recht jene eines damals jungen Philosophen wie Nietzsche - in besonderem Masse nach einem Entwicklungsnarrativ des Denkers und seiner Werkkohärenz verlangen.

In diesem Kontext hervorzuheben ist jedoch ein unbelegter Hinweis aus der Kröner Klassiker-Ausgabe von Nietzsches Werken, in welcher der Wanderer 1919 erschien. In dieser Ausgabe bilden Menschliches und die Vermischten Meinungen zusammen den dritten Band, während der Wanderer mit der Morgenröte den vierten Band bildet. Diese editorische Entscheidung erfolgte gemäss Nachbericht nicht zufällig:

Wir waren nämlich durch den Plan der vorliegenden Ausgabe genöthigt, diese beiden Aphorismensammlungen [Vermischte Meinungen und Wanderer] in zwei verschiedene Bände wiederum zu trennen, doch muss ausdrücklich erwähnt werden, dass diese Trennung sich nicht nur äusserlich rechtfertigt, sondern dass sich auch innerliche Gründe dafür finden. Nietzsche hat selbst zu Peter Gast gesagt, dass die Vereinigung «ein wenig gewaltsam» wäre, denn in der Tat, es klingt ein ganz anderer Klang aus dem «Wanderer und sein Schatten» als aus den anderen Aphorismensammlungen von «Menschliches, Allzumenschliches.» 85

Leider ist nicht weiter bekannt, wann Nietzsche dies zu Gast gesagt hat. Es würde jedoch die vielen Befunde bestätigen, welche in dieser Dissertation präsentiert werden.

808 unverkaufte Exemplare auf Schmeitzners Inventarliste, vgl. Schmeitzner an N., 1.7.1886, Nr. 387, KGB III 4, S. 191. Die Restexemplare von Menschliches bekamen eine neue Titelseite, eine Vorrede und ein Gedicht mit dem Titel «Unter Freunden» am Ende des Buches.

84 MA II, Vorrede 2, KSA 2, S. 371.

85 Nietzsche-Archiv 1919, S. 566 f. Leider konnte ich für die mutmassliche Aussage von Gast keinen Beleg festmachen. 
Durch die Neuausgabe von 1886 war eine Interpretationsweise angestossen, die bis heute andauert. Claus-Arthur Scheier deutet die Zusammenführung der Vermischten Meinungen und des Wanderers sogar als Ehre, weil Nietzsche diese Bücher von Anhängen zu einem «eigenständigen zweiten Band» «erhob». ${ }^{86}$ Die Formulierung moniert nicht nur den Status «letzter Hand», sondern mythologisiert diesen zur verbesserten und gültigen Gesamtausgabe. 87

\subsubsection{Eigenständige Produktion vs. neun Hauptstücke}

Die lose Anordnung der Aphorismen ist beim Wanderer besonders auffällig: War Menschliches noch in neun thematische «Hauptstücke» eingeteilt, gibt es in den Vermischten Meinungen und im Wanderer keine strukturierenden Zwischentitel. Im Vorwort der englischen Werkausgabe bezeichnet der Herausgeber Gary Handwerk deshalb die beiden Bücher als «highly miscellaneous and unordered» und im Vergleich zu Menschliches «self-evidently less structured».88 Joel Westerdale konstatiert einen «apparent lack of systematic completion». 89 Dies entging auch Peter Gast nicht, der in seiner 1894 herausgegebenen Werkausgabe ein Aphorismen-Register aller drei Teilbände veröffentlichte..$^{90}$ Das Aphorismenregister sollte für die Leser als Inhaltsverzeichnis dienen, indem es die Einteilung der neun Hauptstücke auf die Vermischten Meinungen und den Wanderer übertrug. Seither wird davon ausgegangen, dass für alle drei Aphorismenbücher derselbe Buchaufbau in neun Hauptstücken gelte: «Dem aufmerksameren Leser konnte nicht entgehen, daß die «vermischten〉 Meinungen und Sprüche wie dann noch einmal der Wanderer der thematischen Reihung des ersten Bands folgen [...].» ${ }^{11}$ Es stellt sich deshalb die Frage, ob Nietzsche diese «thematische[ ] Reihung» in irgendeiner Weise angestrebt hat, oder es sich um eine nachträgliche Interpretation der Herausgeber seiner Werke handelt?

86 So in der offiziellen Ausschreibung vom Meiner-Verlag: https://meiner.de/menschlichesallzumenschliches-2-neue-ausgabe-2067.html [07.04.2017].

87 Scheier reklamiert für seine Ausgabe «die von Nietzsche selbst gewollte und kritisch kommentierte Ausgabe ganz eigener Art» (2013b, S. V-VI). Für eine kritische Rezension an dieser Ausgabe vgl. Reschke 2015b. Zur Problematik des Prinzips «letzter Hand» vgl. Benne 2015 a, S. 267.

88 Handwerk 2012, S. 568. Auch der frühere Herausgeber August Horneffer bemängelt dies: «Bemerkenswert ist übrigens, daß auch die Bildung der Schubfächer, in die der Stoff hineingeschüttet wurde, viele Mühe kostete und doch nicht gut glückte; die Titel sind zum Teil recht vag, wurden auch schon bei den Vermischten Meinungen weggelassen; doch blieb die Ordnung dieselbe.» (Horneffer 1906, S. 75).

89 Westerdale 2013, S. 60.

90 Vgl. GAG, Bd. 3, S. 369-379. Zur GAG vgl. Hoffmann 1991, S. 715-718.

91 Scheier 2013a, S. 317. 


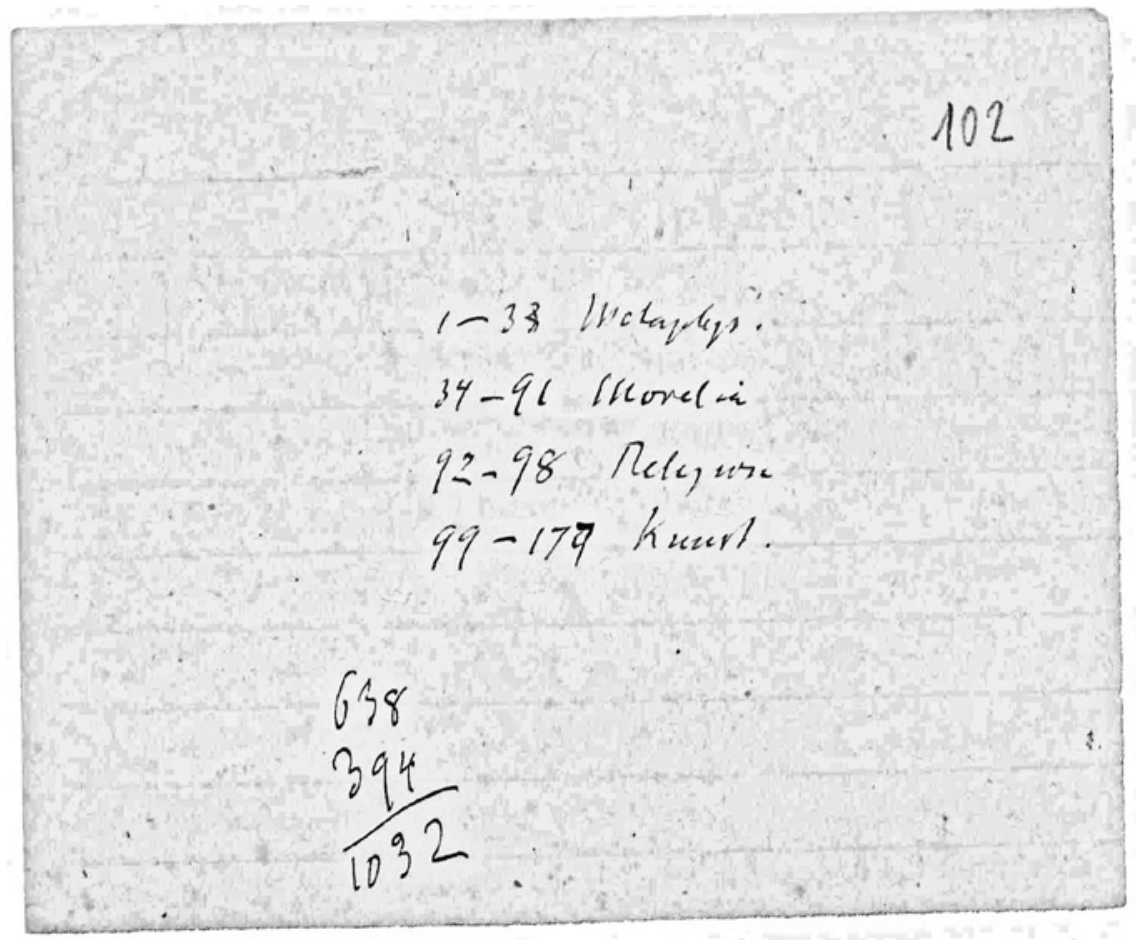

Abb. 5 Einteilungsentwurf für die Aphorismen der Vermischten Meinungen

Dazu muss zunächst bestimmt werden, ob es von Nietzsches Hand entsprechende Zeugnisse in den Manuskripten zu den Vermischten Meinungen und zum Wanderer gibt.

Während der Arbeit an den Vermischten Meinungen finden sich mehrere Versuche einer Gliederung in Hauptstücke. Zwei Entwürfe vom Sommer 1878 sehen zwar Hauptstücke vor, jedoch andere als jene von Menschliches. ${ }^{92}$ Erst auf einem im Goethe- und Schiller-Archiv in Weimar befindlichen Zettel lässt sich eine Einteilung finden, welche dem Schema von Menschliches folgt (Abb. 5) ${ }^{93}$ Es handelt sich aber nicht um eine Einteilung der finalen Publikation, da Nietzsche nur mit 394 statt mit den letztlich publizierten 408 Aphorismen rechnet. Trotzdem kann davon ausgegangen werden, dass Nietzsche die ausgeschnittenen Aphorismenzettel nach diesem Schema zumindest teilweise ordnete.

92 Vgl. in N II 7 vom Sommer 1878 die beiden Listen NL 1878, 30[53], KSA 8, S. 530; NL 1878, $30[166]$, KSA 8, S. $55^{2}$.

93 GSA 71/230,2: Blatt 102. Vgl. auch KGW IV 4, S. 560, Fussnote 118. 
In den Notizbüchern und Arbeitsheften von 1879 findet sich noch keine erkennbare Ausrichtung auf die neun Hauptstücke. Erst im Druckmanuskript sind auf der Rückseite einiger Stutzblätter lateinische Überschriften zu lesen, die von der Nummerierung her den Hauptstück-Titeln aus Menschliches entsprechen (Tab. 1). Nietzsche benutzte diese Blätter als Umschläge, in welche er die reingeschriebenen und überarbeiteten Zettel (die späteren Aphorismen) einordnete (Abb. 11 und 12). Das Vorgehen ähnelt daher der gelehrten Lesetechnik, Exzerpte nach bestimmten Themen («Loci communes») zu ordnen. ${ }^{94}$ Die lateinischen «Loci communes» sind im Unterschied zu den literarischen Hauptstücktiteln von Menschliches zunächst eine Produktionstechnik und kein zur Lektüre gedachter Text. Es handelt sich bei diesen Falzblättern zu keinem Zeitpunkt um Zwischentitel im Druckmanuskript. Warum Nietzsche keine Zwischentitel ins Buch aufnahm, ist nicht eindeutig erklärbar. Sicher ist, dass er anders als in Menschliches sehr ungleiche Mengen von thematischen Aphorismen anfertigte. So fällt die Anzahl an Aphorismen zu Religion und Familie gering aus. Nietzsche strebte 1879 keine ausgewogenen Hauptstücke an, wie dies in Menschliches der Fall war. Da die ursprüngliche Zettelordnung nicht mehr rekonstruiert werden kann, rühren zumindest die genauen Einteilungen von den individuellen Leseeindrücken der Herausgeber her. Die ersten drei thematischen Blöcke können übereinstimmend bestimmt werden, während bei den anderen Hauptstücken viele umliegende Aphorismen ebenso gut zum einen oder anderen Thema passen würden. Das zeigt sich auch an den zunehmenden Abweichungen von Zwischentiteln und Einteilungen. Ein Beispiel sei hier gegeben: Das Hauptstück über die Religion beginnt gemäss allen Herausgebern ab Aphorismus 72, in dem Sokrates' ironisch-lustiger Umgang mit der griechischen Religion angedeutet wird. ${ }^{95}$ Der Aphorismus 66, unter Metaphysik eingeteilt, besteht aus einem kurzen Dialog zwischen Philipp Melanchthon und Martin Luther, in dem es um den Zusammenhang von Predigten und Glaubenszweifeln geht. ${ }^{96}$ Angesichts der Thematik und der geringen Anzahl von Aphorismen zu Religion hätte dieser Aphorismus auch in den Umschlag mit religiösen Aphorismen gepasst. Zumindest zeigt das Beispiel zusammen mit den in der Publikation fehlenden Zwischentiteln, dass Nietzsche eine lose und ausgewogene Ordnung hinnahm, wenn nicht sogar intendierte.

94 Vgl. Décultot 2014a.

95 WS $72, \mathrm{KSA}_{2}, \mathrm{~S}_{5}{ }^{84 f}$.

96 Vgl. WS 66, KSA 2, S. $5^{82}$. 
тАв. 1 Die Einteilung vom Wanderer in neun Hauptstücke (eigene Darstellung) ${ }^{97}$

\begin{tabular}{|c|c|c|c|c|c|}
\hline WS (D 13) & $\begin{array}{l}\text { MA } \\
\text { (Hauptstücke) }\end{array}$ & P. Gast & $\begin{array}{l}\text { E. Förster- } \\
\text { Nietzsche }\end{array}$ & C. Scheier & G. Handwerk \\
\hline $\begin{array}{l}\text { «I } \\
\text { Metaphysica» } \\
\text { (Blatt 3o verso) }\end{array}$ & $\begin{array}{l}\text { I. «Von den } \\
\text { ersten und } \\
\text { letzten Dingen» }\end{array}$ & $\begin{array}{l}\text { «Zur Auslegung } \\
\text { von Welt und } \\
\text { Leben»1-17 }\end{array}$ & $1-17$ & $\begin{array}{l}\text { «Meta- } \\
\text { physik» } \\
1-17\end{array}$ & $\begin{array}{l}\text { «metaphysics» } \\
\text { 1-17 }\end{array}$ \\
\hline \multirow[t]{2}{*}{$\begin{array}{l}\text { «II Moralia» } \\
\text { (Blatt } 27 \text { verso) }\end{array}$} & $\begin{array}{l}\text { II. «Zur } \\
\text { Geschichte der } \\
\text { moralischen } \\
\text { Empfindungen» }\end{array}$ & $\begin{array}{l}\text { «Moralist und } \\
\text { Moral» 18-71 }\end{array}$ & $18-71$ & $\begin{array}{l}\text { «Moral» } \\
18-71\end{array}$ & $\begin{array}{l}\text { «morality and } \\
\text { justice» } 18-71\end{array}$ \\
\hline & $\begin{array}{l}\text { III. «Das } \\
\text { religiöse Leben» }\end{array}$ & $\begin{array}{l}\text { «eligiosität» } \\
72-86\end{array}$ & $72-86$ & \begin{tabular}{|l} 
«eligion» \\
$72-86$
\end{tabular} & $\begin{array}{l}\text { «religion» } \\
72-86\end{array}$ \\
\hline $\begin{array}{l}\text { «IV Litteratura } \\
\text { et artes» } \\
\text { (Blatt } 42 \text { verso) }\end{array}$ & $\begin{array}{l}\text { IV. «Aus der } \\
\text { Seele der } \\
\text { Künstler und } \\
\text { Schriftsteller» }\end{array}$ & $\begin{array}{l}\text { «Ü̈nstlerische } \\
\text { Dinge» } 87-170\end{array}$ & $87-170$ & $\begin{array}{l}\text { «unst» } \\
87-169\end{array}$ & $\begin{array}{l}\text { «style»87-147 } \\
\text { «music» } \\
148-169\end{array}$ \\
\hline $\begin{array}{l}\text { «V Cultura» } \\
\text { (Blatt 6o verso) }\end{array}$ & $\begin{array}{l}\text { V. «Anzeichen } \\
\text { höherer und } \\
\text { niederer Cultur» }\end{array}$ & $\begin{array}{l}\text { «Auf mancherlei } \\
\text { Kulturstufen» } \\
\text { 171-240 }\end{array}$ & $171-233$ & \begin{tabular}{|l} 
«Historie» \\
$170-233$
\end{tabular} & \\
\hline $\begin{array}{l}\text { «VI homo } \\
\text { societatis» } \\
\text { (Blatt } 62 \text { verso) }\end{array}$ & $\begin{array}{l}\text { VI. «Der Mensch } \\
\text { im Verkehr» }\end{array}$ & $\begin{array}{l}\text { «Das gesellige } \\
\text { Leben» 241-264 }\end{array}$ & $234-264$ & $\begin{array}{l}\text { «Gesell- } \\
\text { schaft» } \\
233-269\end{array}$ & $\begin{array}{l}\text { «youth and } \\
\text { age» } \\
265-69\end{array}$ \\
\hline $\begin{array}{l}\text { «VII feminae } \\
\text { liberigell» } \\
\text { (Blatt 64 verso) }\end{array}$ & $\begin{array}{l}\text { VII. «Weib } \\
\text { und Kind» }\end{array}$ & $\begin{array}{l}\text { «er jüngere } \\
\text { Mensch» } 265^{-274}\end{array}$ & $265^{-274}$ & $\begin{array}{l}\text { «amilie» } \\
270-274\end{array}$ & $\begin{array}{l}\text { «gender» } \\
270-74\end{array}$ \\
\hline $\begin{array}{l}\text { «VIII res } \\
\text { publica» } \\
\text { (Blatt } 71 \text { verso) }\end{array}$ & $\begin{array}{l}\text { VIII. «Ein Blick } \\
\text { auf den Staat» }\end{array}$ & $\begin{array}{l}\text { «Im demokrati- } \\
\text { schen Zeitalter» } \\
275^{-293}\end{array}$ & $275^{-294}$ & $\begin{array}{l}\text { «Staat» } \\
275^{-296}\end{array}$ & $\begin{array}{l}\text { «politics and } \\
\text { economics» } \\
275^{-294}\end{array}$ \\
\hline $\begin{array}{l}\text { «IX homo } \\
\text { solitarius» } \\
\text { (Blatt } 76 \text { verso) }\end{array}$ & $\begin{array}{l}\text { IX. «Der Mensch } \\
\text { mit sich allein» }\end{array}$ & $\begin{array}{l}\text { «Das neue Leben» } \\
294-350\end{array}$ & $295^{-3} 5^{\circ}$ & $\begin{array}{l}\text { «Indivi- } \\
\text { duum» } \\
297-35^{\circ}\end{array}$ & \\
\hline
\end{tabular}

97 Vgl. D 13; MA, KSA 2; GAG, Bd. 3, S. 369-379; Förster-Nietzsche 19o6, S. 473; Scheier 2013a, S. 317; Handwerk 2012, S. 569, Fussnote 25. Handwerk gibt als Einziger zu bedenken, dass die ganze zweite Hälfte des Wanderers durchmischter sei und sich nur noch grobe Muster ausmachen liessen. 


\subsection{Schreibsituation und Entstehung vom Wanderer}

Am 21. Juni 1879 reist Nietzsche nach St. Moritz, wo er bis zum 17. September bleibt. ${ }^{98}$ In dieser Zeit beschreibt er die Notizbücher und Arbeitshefte für den Wanderer. Am 18. Oktober, lediglich vier Monate nach Beginn der Arbeiten, überreicht er das fertige Druckmanuskript dem Verleger, welcher bereits am 18. Dezember die ersten Exemplare versendet. Als Grundlage für die Analyse der Wanderer-Manuskripte ist zunächst die Schreibsituation zu definieren und anschliessend auf Nietzsches Aufenthalt in St. Moritz anzuwenden. Danach wird die materiale Entstehung entlang der Schreibpraktiken und vorhandenen Manuskripte beschrieben.

\subsubsection{Schreibsituation}

Unter Schreiben wird hier die Handlung des Schreibens, unter Schrift einerseits ein Zeichensystem und andererseits die statische sowie sichtbare Gestalt von Schreibakten verstanden. ${ }^{99}$ Schreiben ist immer ein Prozess, der sich durch materiale Praktiken und innerhalb von Situationen vollzieht. Eine Situation bezeichnet die räumlichen sowie zeitlichen Verhältnisse und Umstände, in denen sich entweder jemand bzw. etwas befindet oder in denen etwas geschieht. Eine Schreibsituation beschreibt deshalb den Umstand, dass das Schreiben in einem Zusammenhang verschiedener Faktoren situiert ist (Schreibverfahren, Umgebung und Alltag). Mit der Schreibsituation verschiebt sich der Fokus weg von der intentio auctoris und hin zu einem Ensemble von Dingen, Praktiken, Umgebungen und Umständen. Schreibsituationen stellen sich ein, sobald jemand schreibt. Sie können aber auch auf ein bestimmtes Schreiben hin konzipiert und modifiziert werden. Dies geschieht beispielsweise durch die Orientierung an einem Schriftprodukt, einer Tagesstruktur oder dem Aufsuchen bestimmter Umgebungen. Die Schreibsituation soll dem Umstand Rechnung tragen, dass Autorinnen und Autoren beim Schreiben funktionierende Konstellationen nutzen, die sich weit über den Schreibakt hinaus erstrecken.

Jede Schreibsituation ist eingebunden in den Alltag. Dies macht den Begriff einerseits unscharf, eröffnet aber das Potenzial, eine Vielfalt von individuellen Schreibpraktiken zu erfassen sowie Lebensumstände zu thematisieren, welche die Schreibsituation formieren. Das ist nützlich, weil sich die Schreib-

98 Das Ankunftsdatum folgt u.a. aus dem Brief von N. an Franziska N, 21.07.1879, Nr. 867, KGB II 5, S. 427. Dort schreibt Nietzsche am 21. Juli, dass er nun einen Monat in St. Moritz sei. Vgl. auch N. an Schmeitzner, 18.12.1879, Nr. 915, KGB II 5, S. 471.

99 Vgl. für eine ausführlichere Diskussion Zanetti 2012b, S. 31-34. 
situationen ab 1800 individualisieren. ${ }^{100}$ Das gilt besonders für das mobile Schreiben, welches immer in «soziale Orte und Situationen eingebettet» ist, wobei sich durch diese Einbindung auch die Umgebung stärker ins Schreiben «einschreibt». ${ }^{101}$ Je beiläufiger und routinierter das mobile Notieren ins Leben des Philosophen eingebettet ist, desto mehr äusserliche Einflüsse können sich in sein Notizbuch einschreiben und ins Schreiben 〈hineinrutschen〉. Notizbücher und ihre Umgebungen stehen in einem wechselseitigen Verhältnis. ${ }^{102}$ Es wird noch zu zeigen sein, dass Nietzsche es darauf anlegte, seine Notizbücher in den spezifischen Umständen seiner St. Moritzer Spaziergänge zu situieren. Es gilt deshalb für Nietzsche, was Goethe 1819 über seine Schriften sagte: «Dasjenige was von meinen Bemühungen im Drucke erschienen, sind nur Einzelheiten, die auf einem Lebensboden wurzelten und wuchsen, wo Thun und Lernen, Reden und Schreiben, unablässig wirkend einen schwer zu entwirrenden Knaul bildeten.» ${ }^{103}$ Die Schreibsituation ist dieser hybride Knäuel. Sie bezeichnet den gleichberechtigten Anteil von Autor und Situation am Schreiben. Der Nietzsche von 1879 begreift die klimatischen und diätetischen Umstände als zentrale Dimensionen des Schreibens und experimentiert in St. Moritz strategisch mit ihnen. Das Philosophieren unterwegs und im Freien ist bei Nietzsche deshalb über die Schreibpraktik hinaus eine philosophische Stellungnahme, die werkpolitische, moralische und philosophische Konsequenzen nach sich zieht. Nietzsche stilisiert und inszeniert die St. Moritzer Schreibsituation philosophisch, lebenspraktisch und literarisch. Am deutlichsten wird dies in der Titelwahl «St. Moritzer Gedanken-Gänge» bzw. «Der Wanderer und sein Schatten». ${ }^{104}$

Ich wähle den Begriff Schreibsituation in Anlehnung an den in der Literaturwissenschaft gebräuchlichen Begriff der «Schreibszene». Rodolphe Gasché definiert die Writing Scene als Thematisierung des Schreibens im Schreibakt. ${ }^{105}$

100 Krauthausen 2010, S. 16: «Die Formalisierung des Notierens wird niederschwelliger, die Praxis ist zunehmend durch den Schreibenden beziehungsweise eine spezielle Schreibsituation bedingt.»

101 Stingelin/Thiele 2010, S. 18, 20.

102 Vgl. Hoffmann 2010, S. 91: «Ein Notizbuch gehört aber nicht nur Umgebungen an, in denen es gebraucht wird. Es bildet ebenso dem Gebrauch - dem Vorgang des Notierens eine Umgebung.»

103 Goethe 1904, S. 81. Diesen Hinweis verdanke ich Benne 2015a, S. 265.

104 Vgl. M I 2, S. 91 bzw. NL 1879, 43[Titel], KSA 8, S. 610.

105 Der Begriff der Schreibszene wurde von Jacques Derrida («la scène de l'écriture») und Rodolphe Gasché im heute verwendeten Sinne geprägt, vgl. Derrida 1967 und Gasché 1977, S. 166: «The scene of writing condenses the act of writing into a figure which itself is a result of this same action. Every representation of the scene of writing, and this is equally true for its theoretical comprehension, is subordinated to the process of writing 
Ihn interessiert die Selbstbezüglichkeit des Schreibakts und seine szenische Inszenierung: «das Theaterstück des Schreibaktes». ${ }^{106}$ Die Verwendung im deutschsprachigen Raum fokussiert demgegenüber mehr auf den körperlichen und materialen Schreibakt: So kann in Schreibszenen gemäss Rüdiger Campe «ein nicht-stabiles Ensemble von Sprache, Instrumentalität und Geste» thematisiert werden. ${ }^{107}$ Es ist ein grosses Verdienst dieses Ansatzes, dass das Schreiben konsequent als Praktik erforscht wird. Schreiben ist ein heterogener Prozess, in dem unterschiedliche Ebenen wie Semantik, Techniken und Körper zusammenkommen. Campe geht es mit der «Schreibszene» um zwei Wortverwendungen von «écrire» und «écriture»: Es geht ihm erstens um «innerliterarische Thematisierungen oder literaturnahe Regulierungen des 〈Schreibens»». ${ }^{108}$ Von diesem Aspekt lässt sich die Schreibsituation abgrenzen, zumal sie auch unabhängig von ihrer innerliterarischen Thematisierung die literaturfernen Regulierungen des Schreibens wie etwa den Alltag, das Klima oder die Diät thematisiert. ${ }^{109}$

Durchlässiger ist die Abgrenzung von der zweiten Wortverwendung, welche «immer auch eine Praktik, ein Repertoire von Gesten und Vorkehrungen» impliziere. ${ }^{110}$ Denn Martin Stingelin hat den Begriff der «Schreibszene» weiterentwickelt und ausgeweitet.111 Zunächst interessierten ihn poetologische Problemstellungen wie Stockungen und Störungen des Schreibprozesses: Das Schreiben halte sich «an sich selbst» auf (am Schreibzeug, den Schreibmaterialien, den Schreibmöbeln etc.), weshalb Stingelin in solchen Fällen von

so as to be a mere coming to halt of a writing nevertheless undoing this figure again in its movement.» Gasché interpretiert in diesem Aufsatz das Kapitel «Cetology» von Herman Melville's Moby Dick als Selbstreflexion über die Produktion von Texten.

106 Benne 2015a, S. 601.

107 Campe 1991, S. 760. Damit rückt alles in den Blick, was an der Schreibpraktik teilhat: « Die Schreibszene> kann einen Vorgang bezeichnen, in dem Körper sprachlich signiert werden oder Gerätschaften am Sinn, zu dem sie sich instrumental verhalten, mitwirken - es geht dann um die Arbeit der Zivilisation oder den Effekt von Techniken.» (ebd.)

108 Campe 1991, S. 759.

109 Vgl. die von Benne benannte Gefahr des Schreibszenenbegriffs, «bestimmte «materiale» Aspekte des Schreibens auf Kosten anderer zu profilieren» (Benne 2015a, S. 6o2f.).

110 Campe 1991, S. 759.

111 Im Anschluss an Campe hat Stingelin die Schreibszene weiter differenziert, als «die historisch und individuell von Autorin und Autor zu Autorin und Autor veränderliche Konstellation des Schreibens, die sich innerhalb des von der Sprache (Semantik des Schreibens), der Instrumentalität (Technologie des Schreibens) und der Geste (Körperlichkeit des Schreibens) gemeinsam gebildeten Rahmens abspielt [...].» (Stingelin 2004, S. 15). 
«Schreib-Szenen» spricht. ${ }^{112}$ Die Aufmerksamkeit richtete sich zunehmend auch auf situative Aspekte. Es ist kein Zufall, dass bei der Untersuchung mobiler Schreibweisen vermehrt die «Umgebung» und die «Situation» in den Blick rücken: «Das mobile Schreiben läßt sich von der Umgebung nicht abtrennen, vielmehr ist es in soziale Orte und Situationen eingebettet. Es vollzieht sich inmitten gesellschaftlicher Situationen und ist auf vielfältige Weise verknüpft und durchwirkt von anderen Raum- und gesellschaftlichen Praktiken.» ${ }^{113}$ Stingelin und Thiele versuchen diese Ausweitung weiterhin unter dem Begriff der «Schreibszene» zu fassen: Denn weitet man die von Campe erwähnten Gesten, Vorkehrungen und Praktiken auf den ganzen Körper, die Fortbewegungsweisen und den Alltag aus, so liessen sich tatsächlich mit der obigen Schreibszenen-Definition auch viele situative Aspekte untersuchen. ${ }^{114} \mathrm{Da}$ im Folgenden zwischen Aspekten des Schreibakts und der Schreibsituation differenziert wird, soll die «Geste des Schreibens» im Sinne Vilem Flussers auf die mit dem konkreten Schreibakt verbundenen Dimensionen bezogen werden: «Um schreiben zu können, benötigen wir - unter anderen - die folgenden Faktoren: eine Oberfläche (Blatt Papier), ein Werkzeug (Füllfeder), Zeichen (Buchstaben), eine Konvention (Bedeutung der Buchstaben), Regeln (Orthographie), ein System (Grammatik), ein durch das System der Sprache bezeichnetes System (semantische Kenntnis der Sprache), eine zu schreibende Botschaft (Ideen) und das Schreiben.» ${ }^{115}$ Der erweiterte «Schreibszene»-Begriff würde so gesehen durch den wegfallenden Fokus auf den Schreibakt unscharf und ist zudem durch den Aspekt des Szenischen für Situationen, Umgebungen oder Diäten weniger geeignet. ${ }^{116}$ Daher akzentuiere ich nicht den Akt und die Szene des Schreibens, sondern die Situation. Dies soll im Folgenden

112 Vgl. Stingelin 2004, S. 15: «wo sich dieses Ensemble in seiner Heterogenität und NichtStabilität an sich selbst aufzuhalten beginnt, thematisiert, problematisiert und reflektiert, sprechen wir von 〈Schreib-Szene〉.»

113 Stingelin/Thiele 2010, S. 18. Auch Hoffmann 2010 akzentuiert die «Umgebungen» und benutzt das Wort «Szene» primär für die Analyse einer inszenierten Fotografie von Ernst Mach (S. 106).

114 Stingelin spricht in einem entsprechenden Handbuch-Artikel explizit von einer Erweiterung des «Schreibszene»-Begriffs (vgl. 2013, S. 100).

115 Flusser 1994, S. 33.

116 Das zeigt sich auch an der jüngst vorgenommenen Übertragung des Schreibszene-Konzepts auf das Lesen. So heisst es im Ausschreibungstext einer Tagung zu «Leseszenen»: «Grundsätzlich soll es daher weniger um eine Untersuchung des Phänomens des Lesen im Sinne von Lesegewohnheiten und Lesepraktiken gehen, [...], als vielmehr (1) um die Reflexion des Lesens als Kulturtechnik im literarischen Text, [...] sowie (2) um ästhetische bzw. ikonographische Leseszenen - in Analogie zur Schreibszene [...].» (Fliedl u.a. 2018). 
auf den Wanderer angewendet werden:Nach der Beschreibung der historischen und biografischen St. Moritzer Schreibsituation, wird auf den praktischen Ablauf der Buchproduktion eingegangen. In späteren Kapiteln wird die Schreibsituation zu Nietzsches Philosophie in Bezug gesetzt: besonders zur Autorschaft (3.1.3), zur Diätetik (3.3.5), zur Philosophie des Werdens (4.2) und zum Experiment (4.3).

\subsubsection{Moderne Kurortphilosophie vs. heroische Idylle}

Mit Nietzsche verbindet man gemeinhin abgelegene, kleine und ruhige Bergdörfer. Dem muss ebenso für St. Moritz wie für Wiesen, Rosenlauibad und Sils-Maria widersprochen werden. Das Oberengadin erfuhr ab den 186oer Jahren eine enorme touristische Aufwertung und wurde durch eine ertragreiche Aktiengesellschaft verwaltet. Die Engadiner Berglandschaft wurde strategisch beworben, gepflegt und inszeniert. ${ }^{117}$ So findet sich 1878 eine Ausgabe der populären Reiseprospekt-Reihe Europäische Wanderbilder zum Oberengadin. Im selben Jahr schreibt Johann Melchior Ludwig über das Oberengadin: «Etwa 10,00o Vertreter aller Nationen überfluthen jährlich das früher so stille Thal [...].»118 Der satirische Reiseroman Tartarin in den Alpen von Alphonse Daudet parodierte die damaligen Ausmasse des Schweizer Tourismus: «Die Schweiz, Herr Tartarin, ist gegenwärtig nur noch ein grosser vom Juni bis October geöffneter Kursaal, ein Casino-Panorama, wohin man aus allen vier Himmelsrichtungen zu seiner Zerstreuung sich begiebt, [...].»119

Besonders das damalige St. Moritz war ein boomender Kur- und Tourismusort (Abb. 6 und 7). Schon 1873 hatten St. Moritz und das um die Quellen gelegene St. Moritz Bad eine Gästekapazität von 1460 Gästen. ${ }^{120}$ Ein amüsanter Reisebericht aus dem Jahr 1870 zeugt von einer gnadenlosen Jagd auf Hotelzimmer im überfüllten St. Moritz. ${ }^{121}$ Ärzte, Ratgeberliteratur und Werbeanzeigen empfahlen den hochgelegenen Kurort und seine Eisenquellen für eine grosse Anzahl von körperlichen und psychischen Leiden. ${ }^{122}$ In St. Moritz und Umgebung wurden Schutzmassnahmen gegen Unwetter ergriffen, bequeme Spazierwege gebaut, Telegrafie- und Postbüros eingerichtet und sogar der

117 Vgl. Margadant/Maier 1993, S. 140-146 sowie das Kapitel «Alpines Grand Hotel» in Seger 2005, S. 15-106.

118 Ludwig 1878, S. 467.

119 Daudet 1886, S. 103.

120 Robertson 1909, S. 34, 36.

121 Vgl. für den «Struggle for rooms» Yeo 1870, S. 15-20.

122 Vgl. Meyer-Ahrens 186o, Bd. 2, S. 610-705. Nietzsches 1879 genannte drei Grundattribute des Denkers - Ruhe, Grösse, Sonnenlicht - gehören zum touristischen Diskurs um St. Moritz. Vgl. etwa Ludwig 1878, der die Kraft der Sonne, die vielen Sonnentage, die Luft, den Luftdruck, die Landschaft und vieles mehr am Ober-Engadin lobt. 
landwirtschaftliche Umgang mit Dünger und Mist reguliert. ${ }^{123}$ Bei der Trinkhalle gibt es kleine Souvenirshops und im Dorf viele Läden. ${ }^{124}$ Die aus Nietzsches Notizbüchern ersichtlichen Spazierwege sind Gegenstand der meisten Wanderführer und von den zahlreichen Kurgästen rege frequentiert. Zudem klettert man im umliegenden Gebirge und segelt auf den Oberengadiner Seen. Angesichts der ersten elektrischen Glühlampe, welche im Sommer 1879 im Hotel Kulm leuchtete, erweckte St. Moritz beim zeitgenössischen Besucher den Eindruck einer Kleinst-Metropole. ${ }^{125}$ Nimmt man hinzu, dass der im Bau befindliche Gotthardtunnel ein häufiges Gesprächsthema der Touristen war, so mutet der Aphorismus $278 \mathrm{im}$ Wanderer sehr zeitgemäss an: «Prä mis s en des Maschinen-Zeitalters. - Die Presse, die Maschine, die Eisenbahn, der Telegraph sind Prämissen, deren tausendjährige Conclusion noch Niemand zu ziehen gewagt hat.» ${ }^{126}$

Nietzsche berichtet 1874 aus dem bündnerischen Bergün: «Sonst gehen bis zu hundert Menschen täglich hier mit Post vorüber und essen in diesem Hause, so dass wir mitunter zu zwei, aber dann auch zu 40 Personen zu Tisch sind. Der grösste Theil will nach St. Moritz, bleichsüchtiges und nervenschwaches Volk aus der ganzen Welt zusammengeführt durch die modische Berühmtheit jener Bäder.» ${ }^{127}$ Und noch im Juni 1879: «Der Engadin ist mir durch den Überfluß von Deutschen und Baslern fast unbetretbar, das sehe ich jetzt ein (auch s ehr theuer).» ${ }^{128}$ Zwei Wochen später hat er das Hochtal nicht nur betreten, sondern dort auch seine «Natur» gefunden: «Aber nun habe ich vom Engadin Besitz ergriffen und bin wie in meinem Element, ganz wundersam! Ich bin mit dieser Natur verwandt. Jetzt spüre ich die Erleichterung. Ach, wie ersehnt kommt sie!». ${ }^{129}$ Als im selben Sommer sein einziger Besucher Franz Overbeck über die kostspielige Reise ins Oberengadin klagt, ärgert sich Nietzsche über das «verflucht theure und ganz überfluthete Hochthal». ${ }^{130}$ Der Massentourismus und die Kommerzialisierung der Kurorte sind Nietzsche

\footnotetext{
123 Der Verschönerungsverein von St. Moritz legte Spazierwege an uvm., vgl. Ludwig 1875, S. 20; Tschudi 1879, S. 431; Margadant/Maier 1993, S. 109f. und $158 f$.

124 Caviezel 1876, S. 75 .

125 Margadant/Maier 1993, S. $92 \mathrm{f}$.

126 WS 278, KSA 2, S. 674.

127 N. an Franziska N., Ende Juli 1874, Nr. 382, KGB II 3, S. $248 f$.

128 N. an Elisabeth N., 7.6.1879, Nr. 853, KGB II 5, S. 416.

129 N. an Overbeck, 23.6.1879, Nr. 859, KGB II 5, S. 420; vgl. auch die Formulierung «m e in e Art Natur» in: N. an Gast, 12.7.1879, Nr. 865, KGB II 5, S. 426. Schon 1877, nach seiner Rückkehr vom Kurort Rosenlauibad im Berner Oberland, schreibt N. an von Meysenbug, Nr. 662, 3.9.1877, KGB II 5, S. 284: «In der Schweiz bin ich mehr i c h, [...]. In den Alpen bin ich unbesiegbar, namentlich wenn ich allein bin und ich keinen andern Feind als mich selber habe.»

$130 \quad$ N. an Overbeck, 12.08.1879, Nr. 872, KGB II 5, S. 434.
} 
keineswegs entgangen. Vielmehr befindet er sich im ständigen Zwiespalt zwischen der von ihm genossenen Landschaft und der touristischen Infrastruktur (Spazierwege, Kurmöglichkeiten, Post und Telegrafie, Schutz vor Naturgefahren etc. einerseits, Touristenmasse, Kommerzialisierung etc. andererseits). Es mag verblüffen, dass der sich als einsam wandernder Philosoph inszenierende Nietzsche in einem modernen Schweizer Kurort weilt, in einer Pension im Dorfkern logiert und sich obendrein im August eine einmonatige Trinkkur in der Trinkhalle von St. Moritz Bad gönnt, wo er täglich mit vielen anderen Gästen und einer noblen Kurhotel-Infrastruktur in Kontakt kommt. ${ }^{131}$ Letztlich zeigt sich darin Nietzsches zwiespältige und wechselhafte Beziehung zum Engadin, welches ihm den besten Kompromiss für seine Ansprüche an Infrastruktur, Diätetik und Landschaft bot. So schreibt er 1881: «Es bleibt doch bei dem Engadin - denn von meinen vielen Versuchen in der Schweiz (vielleicht 20-30) ist der Engadiner der einzige leidlich gelungene.» ${ }^{132}$

Aufgrund der historischen Faktenlage ist es fragwürdig, wenn Martin Pernet in Bezug auf St. Moritz vom «einsame[n] Gebirge» oder von der «lebensfernen Welt jenseits der Vegetationsgrenze, fernab vom Dunst der Täler und dem Getriebe der Menschen» spricht. Bedenkt man die laufende Hochsaison, ist auch folgende Charakterisierung des Oberengadins reichlich übertrieben: «Weideglück und Transzendenz, Eiszeit und utopisches Licht, Hüttenfriede und Gipfeleinsamkeit.» ${ }^{133}$ St. Moritz ist gerade nicht das «äusserste[ ] Gegenbild» einer zunehmenden Industrialisierung. ${ }^{134}$ Die zigfach neu entstehenden Kurorte schufen die Lebensform des Dauergastes. Nietzsche verbrachte während der Abfassung von Menschliches, den Vermischten Meinungen und dem Wanderer einen Grossteil seiner Zeit in Kurorten. ${ }^{135}$ Seine Philosophie entstand nicht in einer archaischen Schweizer Landschaft, sondern in einem «Casino-Panorama». Das erforderte eine beständige Distanzierung zum

\footnotetext{
131 Vgl. Caviezel 1876, S. 73-75.

132 N. an Gast, 23.6.1881, Nr. 119, KGB III 1, S. 95. Vgl. auch N. an Elisabeth N., 12.7.1879, Nr. 866, KGB II 5, S. 426f.: «Die Orte müssen etwas zu ge ri ch te t sein für Kranke; [...].»

133 Pernet 2001, S. 356.

134 Ebd., S. 356.

135 Vgl. Jung 2004, S. 402, Fussnote 35: «1876: März/April: Veytaux b. Montreux, Genf; (Juni: Badenweiler); Okt.: Bex, Ende Okt.-Dez.: Sorrent; 1877: Jan.-Mai: Sorrent; Mai-Juni: Bad Ragaz, Anfang Juli: Rosenlauibad (Kur mit St. Moritzer Wasser [...] Ab 12. Juli: Felsenegg bei Zug, Ende Juli-Ende August: Rosenlauibad (Berner Oberland, bei Meiringen), Felsenegg bei Zug; 1878: März/April: Baden-Baden, Sommer: Kur in lnterlaken; 1879: März/April: Kur in Genf, Mai: Schloss Bremgarten bei Bern; Mai/Juni: Wiesen bei Davos; Juni-Sept.: St. Moritz.»
} 


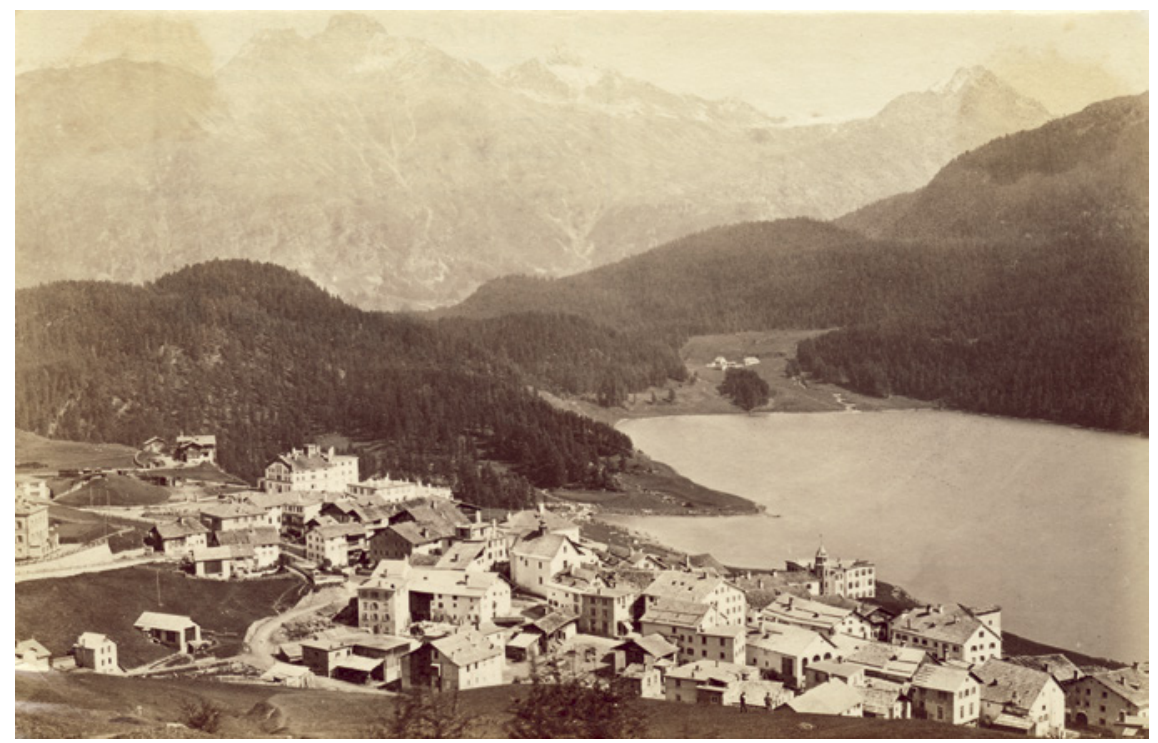

Abb. 6 St. Moritz Dorf, zwischen 1880-1886

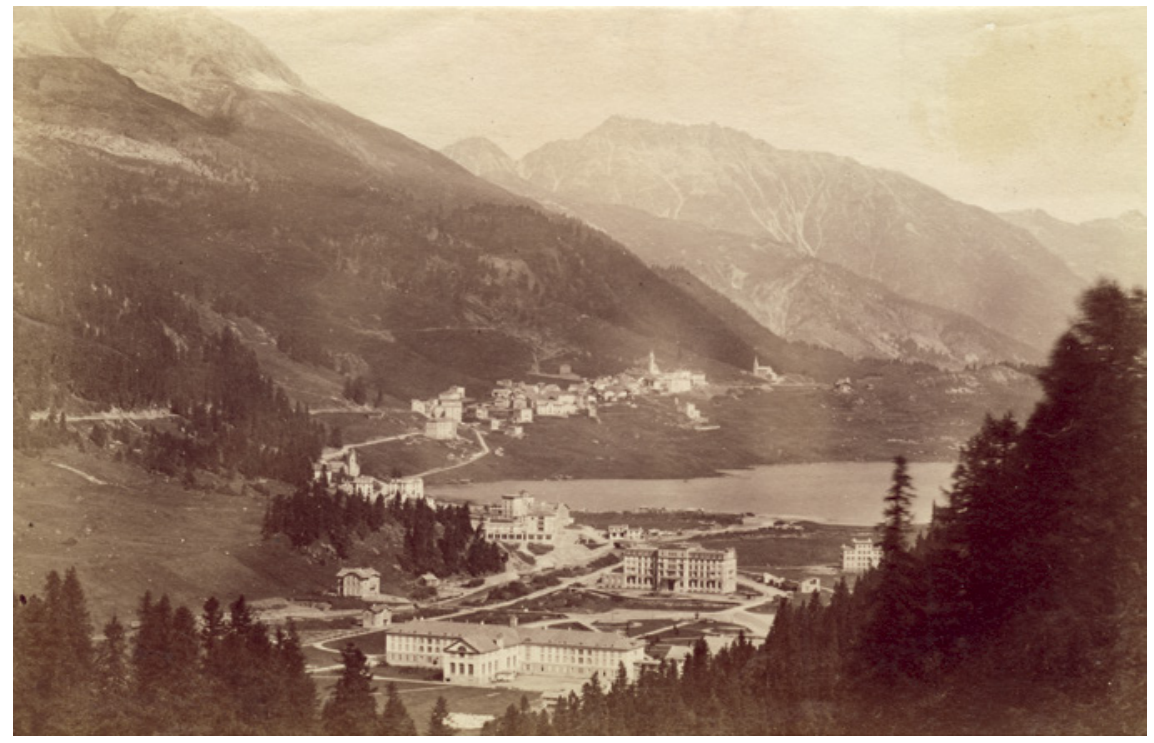

Abb. 7 St. Moritz Bad (vorne) und St. Moritz (hinten), ca. 1877-1879 
Massentourismus, die auch im Wanderer nicht zu kurz kommt. ${ }^{136}$ Beachtet man, dass Nietzsches Aufenthalt in St. Moritz mit der Hochsaison von Juni bis September (15. Juni - 15. September) korrespondiert, kann man durchaus von einer Kurort-Philosophie sprechen. ${ }^{137}$

\subsubsection{Nietzsches Schreibsituation im Sommer 1879}

Es sollen im Folgenden diejenigen Aspekte von Nietzsches Leben im Sommer und Herbst 1879 genannt werden, die mit der Verfertigung und der Inszenierung vom Wanderer zusammenhängen. Gesundheit und Einsamkeit werden darum nicht als Psychologisierung des Autors, sondern als Formierungen der Schreibsituation einbezogen.

Nietzsche kannte das Bündnerland seit seiner Basler Zeit. ${ }^{138}$ Im Sommer 1879 will er ursprünglich von Wiesen aus nach Champfèr, einem kleinen Dorf unweit von St. Moritz (ca. 20 Minuten zu Fuss). ${ }^{139}$ Aus nicht bekannten Gründen hat er sich kurzfristig entschlossen, in St. Moritz zu bleiben. Dort hat es ihm ganz besonders gefallen. So schreibt er am 12. Juli an Peter Gast: «Inzwischen habe ich m e in e Art Natur g e fu n d en [...].» ${ }^{140}$ Seiner Mutter berichtet er: «Wälder, Seen, die besten Spazierwege, wie sie für mich Fast-Blinden hergerichtet sein müssen und die erquicklichste Luft - die beste in Europa - das macht mir den Ort lieb.» ${ }^{141}$ Nietzsche bezeichnet sein Leben Ende 1879 und Anfang 1880 als eine «Spaziergehe-Existenz». ${ }^{142}$ So wundert es nicht, dass der «7/8-Blinde» der täglichen Spaziergänge bald überdrüssig wurde:

136 Vgl. WS 201, KSA 2, S. 641.

137 Vgl. Ludwig 1878, S. 467: «Die Saison beginnt Mitte Juni und schließt Ende September [...].» In diesem Kontext hat mich Rachele Salerno darauf hingewiesen, dass auch Nietzsches wichtige Beschäftigung mit der «vita contemplativa» 1876 im Kontext seiner Beurlaubung steht.

138 So kannte Nietzsche bereits Chur, Flims, Splügen und das Bergün, vgl. Pernet 2001.

139 Damals wurde Champfèr noch «Campfèr» geschrieben. Nietzsche gibt im Juni in Wiesen als zukünftige Adresse nämlich «C a m p fèr, im Oberengadin, poste restante» an (vgl. N. an Elisabeth N., 15.6.1879, Nr. 856, KGB II 5, S. 418; vgl. auch N. an Franz Overbeck, 15.6.1879, Nr. 857, KGB II 5, S. 418). Zudem werden laut Zahlungsbeleg seine Koffer aus Champfèr in die Pension Helvetia von E. Walt-Melcher nach St. Moritz gebracht, vgl. GSA 71/369,5: Blatt 18. Geradezu skurril mutet die Behauptung einer St. Moritzer Festschrift an, gemäss der Nietzsche laut einer unauffindbaren (wohl erfundenen) Briefstelle 1878 in St. Moritz gewesen sein soll (vgl. Berry/Eberhard/Kasper/Küng 1976, S. 38 ).

140 N. an Gast, 12.7.1879, Nr. 865, KGB II 5, S. 426. Schon anlässlich seiner ersten Graubünden-Reise sprach Nietzsche von «m e in e [r] Natur» (N. an Franziska N., 1.10.1872, Nr. 257, KGB II 3, S. 55).

141 N. an Franziska N., Anfang Juli 1879, Nr. 863, KGB II 5, S. 424. Vgl. auch N. an Overbeck, 11.7.1879, Nr. 864, KGB II 5, S. 425 .

142 N. an Overbeck, 11.12.1879, Nr. 913, KGB II 5, S. 470. 
«Ich habe das viele Spazierengehen (ich bin 8 Stunden täglich im Freien!) so satt $[\ldots] .{ }^{143}$

Nietzsche äussert sich einige Male brieflich zu seiner Wohnsituation. So schreibt er an seine Schwester am 24. Juni: «Ich wohne ganz für mich und esse im Zimmer [...].»144 Und dann am 6. Juli 1879: «Ich wohne ganz alle in in einem Hause, und ruhig. Gutes Bett.» ${ }^{145} \mathrm{Am}$ 21. Juli berichtet er seiner Mutter: «Mit dem Ma ge n bin ich jetzt, wo ich mich selber im Zimmer beköstige (Milch Eier Zunge Pflaumen (getrocknete) Brod und Zwieback) völlig in Ordnung. Ich war noch in keinem Hotel oder Restaurant.» ${ }^{146}$ Die einfache Kost und die günstige Logis haben neben seinen Magenproblemen auch finanzielle Gründe: Nietzsche bekommt erst am 19. Juli definitiven Bescheid über seine erweiterte und höhere Rente. ${ }^{147}$

Dass Nietzsche allein wohnt und in keinem Hotel einkehrt, ist zweifelhaft und verstellt den Blick auf die touristische Infrastruktur: Laut einer in Weimar befindlichen Rechnung wohnte Nietzsche vom 21. Juni bis zum 26. Juli bei «E. Walt-Melcher» in St. Moritz (Abb. 8). ${ }^{148}$ Diese Unterkunft lag im Dorfkern gleich am Mauritiusplatz in St. Moritz. Nietzsche logiert vermutlich zudem im August mit Franz Overbeck dort. ${ }^{149}$ Wo Nietzsche sonst noch wohnte, bleibt nach wie vor offen. ${ }^{150}$ Für den Zeitraum vom 26. Juli bis Mitte August sind ein

\footnotetext{
143 N. an Franziska N., 29.8.1879, Nr. 877, KGB II 5, S. 438.

144 N. an Elisabeth N., 24.6.1879, Nr. 860, KGB II 5, S. 421.

145 N. an Elisabeth N., 6.7.1879, Nr. 862, KGB II 5, S. 423.

146 N. an Franziska N., 21.6.1879, Nr. 867, KGB II 5, S. 428.

147 Overbeck an N., 19.7.1879, Nr. 1214, KGB II 6/2, S. 1139-1141.

148 Vgl. GSA 71/369,5: Blatt 18. Diese Rechnung wurde von Volz beachtet (1990, S. 62), während Janz noch vermutete, dass Nietzsche ausserhalb von St. Moritz logierte (1978, S. 20). Caviezel nennt folgende Privatunterkunft: «[Madame] Eva Melcher; 30 [Betten]» (Caviezel 1876, S. 78). Es handelt sich um dieselbe, mittlerweile verheiratete Inhaberin.

149 Overbeck erwähnt den Namen «Pension Helvetia» in einem Brief vom 27.8.1879 an Rohde, vgl. Overbeck/Rohde 1990, S. 39. Der Privatsammler Linard Brüngger konnte anhand einer Visitenkarte die Eigentümerin «E. Walt-Melcher» anhand der Rückseite eines seiner Sammlungsstücke der «Pension Helvetia» zuordnen (Abb. 8).

150 Wie von Volz 1990, S. 62 angemerkt, findet sich in einer Festschrift von St. Moritz die Behauptung, Nietzsche habe als «Patient von Dr. P. R. Berry in der Villetta Grevas, unterhalb des Wohnhauses Villa Du Parc von Dr. Berry» gewohnt (Berry/Eberhard/Kasper/Küng 1976, S. 38; vgl. auch https://de.wikipedia.org/wiki/Peter_Robert_Berry [04.07.2018]). Neben dem Datierungsfehler (1878 statt 1879) fehlen für diese Aussage jegliche Beweise. Nach aufwendigen Nachforschungen lässt sich zumindest Folgendes konstatieren: Die Spekulation um einen möglichen Aufenthalt Nietzsches beim Kurarzt Berry ist auf die Romane von James Schwarzenbach zurückführen. Am Ende vom Regimentsarzt, der auf Memoiren von Peter Robert Berry I basiert, findet sich eine Zeittafel, in der unter 1879 Folgendes zu lesen ist: «Er [Nietzsche] wohnt in der sogenannten Villetta, einer ruhigen Dépendance der Pension Villa Berry, Gästehaus des Kurarztes Dr. P. R. Berry I»
} 


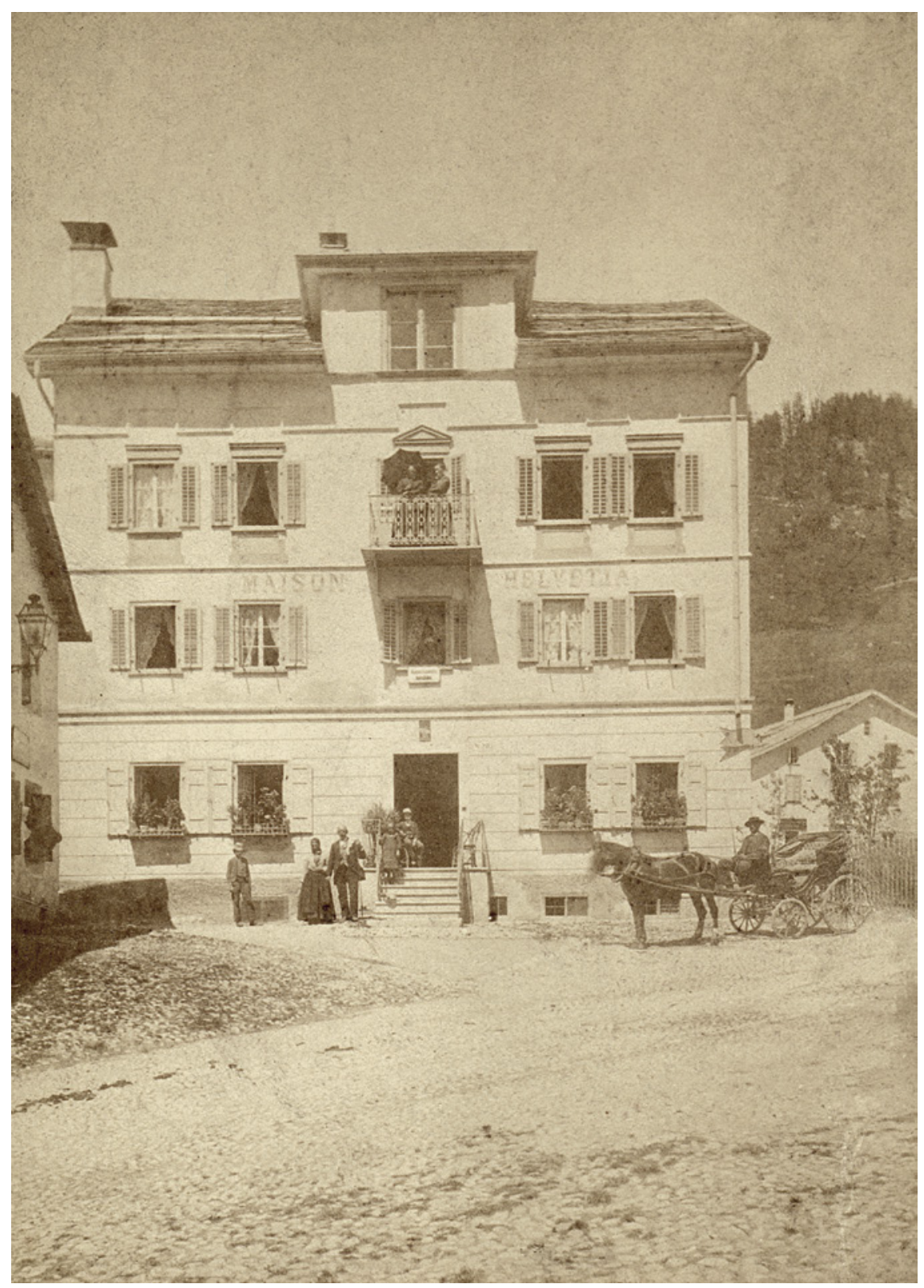

Abb. 8 Maison Helvetia, später Pension Helvetia, in der Nietzsche logierte, undatiert 
missglückter Ausflug ins Unterengadin sowie eine Trinkkur belegt. ${ }^{151}$ Das berühmte Wasser von St. Moritz genoss Nietzsche als Exportprodukt bereits 1877 im Berner Oberland. ${ }^{152}$

Die gesundheitliche Verfassung Nietzsches hat beim Schreiben vom Wanderer eine wesentliche Rolle gespielt. Aus einer Genfer Badekur berichtet Nietzsche im April 1879 an Overbeck: «ich vertrage Lesen und Schreiben nur bis zu 20 Minuten.» ${ }^{153}$ Anders als in Basel hat er in St. Moritz keine Vorleser, mit deren Hilfe er sich grössere Werke hätte aneignen können. Als Nietzsche dann am 18. Dezember 1879 sein Belegexemplar vom Wanderer erhält, schreibt er seinem Verleger: «Die ganze 〈M en s chli ch keit $>$ mit den 2 Anhängen ist aus der Zeit der bittersten und anhaltendsten Schmerzen - und scheint mir doch ein Ding voller Gesundheit. Dies ist mein Triu m ph.»154 Nietzsches Schwester Elisabeth schreibt rückblickend über das Jahr 1879: «das ganze Jahr von Januar 1879 bis Januar 1880 ist das Schlimmste, was Fritz an Leiden und Schmerzen erlebt hat.» ${ }^{155}$ Die starken Augenprobleme erlauben Nietzsche offenbar kaum mehr, längere Zeit zu lesen und zu schreiben. Entsprechend inszeniert Nietzsche in Ecce Homo die Entstehung vom Wanderer:

(Schwarzenbach 1965, S. 308). Diese Angabe scheint sich auf eine retrospektive Kindheitserinnerung des damals 15-jährigen Sohnes des Kurarzts, Peter Robert Berry II (geb. 11.9.1864), zu beziehen. In Belle Epoque, basierend auf Memoiren des Sohnes, wird verschiedentlich auf Nietzsche hingewiesen: Zentral ist eine Kindheitserinnerung, in der Nietzsche den jungen Berry zum Lateinlernen motiviert (Schwarzenbach 1967, S. 74f.; vgl. auch ebd. S. 82 und 243). Der prosaische Stil und die falsche Angabe, Nietzsche habe damals an den Unzeitgemässen Betrachtungen gearbeitet, lassen berechtigte Zweifel aufkommen. Zudem ist diese Kindheitsanekdote in einem vom Berry-Archiv privat zur Verfügung gestellten Memoiren-Transkript um einiges vorsichtiger formuliert: Es ist die Rede von der «Dachkammer, welche im Sommer 1879 Friedrich Nietzsche bewohnt haben dürfte» (II S1 AS 22.069, S. 68 recto; vgl. auch II S 1 KS o6.o2.02, S.5b; Trankskripte liegen mir als Word-Dokumente des Berry-Archivs vor). Die wohl erst in den 189oer-Jahren geschriebenen retrospektiven Memoiren im Kontext einer Prosa-Autobiografie sind kein hinreichender Beleg. Abgesehen davon ist es jedoch gut möglich, dass Nietzsche im Rahmen seiner Gesundheitsprobleme oder seiner Trinkkur mit dem Kurarzt Berry in Kontakt kam. Ich danke an dieser Stelle für die Hinweise von Cordula Seger und Basil Vollenweider.

151 Vgl. N. an Elisabeth N., 14.8.1879, Nr. 873, KGB II 5, S. 435; N. an Elisabeth N., 19.8.1879, Nr. 874, KGB II 5, S. 436. Nietzsche war Anfang August mindestens drei Tage unterwegs.

152 N. an von Meysenbug, 1.7.1877, Nr. 630, KGB II 5, S. 250.

153 N. an Overbeck, 11.4.1879, Nr. 837, KGB II 5, S. 406.

154 N. an Schmeitzner, 18.12.1879, Nr. 915, KGB II 5, S. 471. Bei der «《Menschlichkeit mit den 2 Anhängen» handelt es sich um Menschliches, die Vermischten Meinungen und den Wanderer.

155 Förster-Nietzsche 1914, S. 99. 
[...] im sechsunddreissigsten Lebensjahre kam ich auf den niedrigsten Punkt meiner Vitalität, - ich lebte noch, doch ohne drei Schritt weit vor mich zu sehn. Damals - es war 1879 - legte ich meine Basler Professur nieder, lebte den Sommer über wie ein Schatten in St. Moritz und den nächsten Winter, den sonnenärmsten meines Lebens, als Schatten in Naumburg. Dies war mein Minimum: «Der Wanderer und sein Schatten» entstand währenddem. Unzweifelhaft, ich verstand mich damals auf Schatten... ${ }^{156}$

Es ist dieser Gesundheitszustand, welcher kurz vor dem St. Moritzer Aufenthalt zur definitiven Entbindung von allen beruflichen Tätigkeiten als Basler Professor führt. Sein Haupteinkommen ab 1879 sind die jährlichen 3000 Franken, welche er von der Stadt Basel wegen der Frühpension aufgrund von Invalidität erhält. Nietzsche war de facto arbeitslos und schreibt im Sommer 1879 zum ersten Mal als freier Schriftsteller und «fugitivus errans». ${ }^{157}$ Noch 1878 entspricht dies nicht Nietzsches Selbstverständnis: «Inmitten meiner vollen akademischen Thätigkeit und sehr glücklich, sie wieder ganz auszuüben. Denken Sie, ich sei ein 〈Schriftsteller〉?» 158

Nach der Aufgabe der Professur löst Nietzsche 1879 sein Basler Domizil auf und reduziert seine Bibliothek massiv. Bis auf zwei Koffer verschenkt und verkauft er seine Bücher. ${ }^{159}$ Später stilisiert Nietzsche in Ecce Homo seinen Weggang aus Basel: er sei «erlöst» worden von den Bibliotheken und der «Bücherwürmerei». ${ }^{160}$ Noch 1879 schreibt er rückblickend über seinen St. Moritzer Sommer: «es fehlten Freunde und jeder Verkehr, ich konnte keine Bücher lesen; [...].» ${ }^{161}$ Es muss demgegenüber klar festgehalten werden, dass Nietzsche auch in St. Moritz Bücher liest und anfordert. Dies bezeugen ebenso die Bücherwünsche und Lektüreberichte in Nietzsches Korrespon-

156 EH, KSA 6, S. 264. Vgl. auch EH, KSA 6, S. 326, wo Nietzsche von den «kränksten und schmerzhaftesten Zeiten meines Lebens» spricht. Davon zeugen auch zahlreiche Briefe aus und über diese Zeit.

157 Am 7. März 1879 wurde Nietzsches Entlassung aus dem Pädagogium ohne Kürzung des Lohnes angenommen. Die Freistellung seiner universitären Tätigkeiten erreichte er am 14. Juni 1879 (Falkner an N., 14.6.1879, Nr. 1198, KGB II 6/2, S. 1118). Die offizielle Urkunde wurde am 16. Juni versendet (Speiser an N., 16.6.1879, Nr. 1199, KGB II 6/2, S. 1119). Die Bezeichnung «fugitivus errans», umherirrender Flüchtling, bezieht sich auf Nietzsches nunmehr domizillosen Zustand (N. an Rée, Ende Juli 1879, Nr. 869, KGB II 5, S. 431).

158 N. an Schmeitzner, 16.5.1878, Nr. 722, KGB II 5, S. 328.

159 Vgl. Brobjer 200o, S. 59: «Als N. im Jahre 1879 Basel verließ, wurden einige seiner Bücher zum Haus der Mutter in Naumburg gebracht und eine beträchtliche Anzahl wurde in Zürich bei Frau Rothpletz, der Schwiegermutter seines Freundes Overbeck, verwahrt. [...] Elisabeth N. behauptet, daß N. im Jahre 1879 ebenfalls eine beträchtliche Anzahl Bücher, vor allem philologische, verkauft hat.»

$160 \quad$ EH, KSA 6, S. 326.

161 N. an Gast, 11.9.1879, Nr. 880, KGB II 5, S. 442. 
denz wie auch die vielen Notate und Aphorismen, welche auf Textstellen und Lektüren hinweisen. ${ }^{162}$ Insbesondere die diätetische Ratgeberliteratur und ihr Einfluss auf Nietzsches Denken wird in Kap. 3.3 eingehend behandelt. Wie könnte Nietzsche in St. Moritz zu Büchern gekommen sein? Vermutlich führte er einige Bücher mit sich und könnte sich auch bei den gut ausgestatteten Lesesaal-Bibliotheken einiger Hotels oder Privatpersonen mit Lesestoff versorgt haben. Inwieweit er in St. Moritz davon Gebrauch macht, ist schwierig abzuschätzen, weil Nietzsche auch mit erinnerten Zitaten, Worten, Sätzen und Lese-Eindrücken arbeitet. ${ }^{163}$ Die Aphorismen zu Jean Paul, Lessing, Wieland oder Herder enthalten keine Zitate und bedurften keine Lektüre vor Ort. Es ist aus all diesen Gründen Vorsicht geboten, wenn man vorschnell den Aphorismenstil auf die fehlende Bibliothek, die reduzierte Lektüre oder die schwachen Augen zurückführt.

Des Weiteren hat Nietzsche in St. Moritz bis auf Franz Overbeck keinen Besuch. ${ }^{164}$ Das ganze soziale Umfeld einer regelmässigen Arbeit, und sei es auch nur die Korrespondenz, fiel weg. Seine selbstgewählte Isolation führt anfangs November desselben Jahres zu einem kuriosen Zeitungsbericht der Allgemeinen Schweizer Zeitung (damalige Basler Zeitung), in dem über Nietzsches «angeblichen Tod» spekuliert wird. ${ }^{165}$ Es hat deshalb auch eine soziale

162 Vgl. beispielsweise Carey (vgl. N. an Schmeitzner, 8.6.1879, Nr. 855, KGB II 5, S. 417), Goethe (vgl. N IV 1, S. 48 bzw. NL 1879, 41[68], KSA 8, S. 594), Monod (vgl. N. an Elisabeth N., 24.7.1879, Nr. 868, KGB II 5, S. 43of.) oder Jhering (vgl. N. an Overbeck, 31.7.1879, Nr. 870, KGB II 5, S. 431f.). Auch ein abgeänderter Aphorismus über Frauen und Haustiere war von einer nicht genau feststellbaren Lektüre inspiriert, vgl. KGB II 7/3,1, S. 429. Es findet sich sogar auf Nietzsches St. Moritzer Hotelrechnung eine Buchbestellung, vgl. GSA 71/369,5: Blatt 18. Vgl. für weitere Nachweise von 1879, Brobjer 2008b, S. 218f. Hinzu kommen Lektürepläne wie NL 1879, 39[8], KSA 8, S. 577 und NL 1879, 43[1], KSA 8, S. 610. Überdies hat Nietzsche Zugriff auf Henrik Mohns Grundzüge der Meteorologie (Mohn 1875). Dies ist meines Wissens bis dato nirgends ausgewertet. Ich bin zufällig bei der Recherche zum Aphorismus über die norwegischen «Dunkel-Zeiten» (WS 191, KSA 2, S. 638) darauf gestossen. Mohn schreibt: «In den Gegenden, die innerhalb der kalten Erdgürtel liegen, giebt es im Winter eine Zeit, in welcher die Sonne den ganzen Tag über unter dem Horizonte bleibt. Diese nennt man in Norwegen die Dunkelzeit.» (Mohn 1875, S. 23) Vgl. dazu die entsprechende Notiz in N IV 2, S. 3. Dass es auf derselben Notizbuchseite um das Klima geht, festigt diesen Beleg.

163 Gast berichtet im Vorwort seiner Werkausgabe: ««Mit meinen Citaten steht es schlecht! sagte Nietzsche einmal zu mir - Aber ich kann mich auf meinen Reisen nicht mit Büchern beschleppen und muss meist aus dem Gedächtniss citiren.»» (GAG, Bd. 3, S. XLVIII).

164 Overbeck sah nach seinem Besuch anfangs August in Nietzsches Einsamkeit ein Problem, das es um jeden Preis für die nähere Zukunft zu verhindern gelte, vgl. v.a. seinen Brief an Gast vom 27.8.1879 in Overbeck/Köselitz 1998, S. $29 f$.

165 Am 1o. November schreibt Elisabeth an Nietzsche: «Es war also von Dührings vermeintlichen [sic] Tod die Rede und der Berichterstatter fährt fort: $<[\ldots]$ Der Todtgesagte mag 
Komponente, wenn Nietzsche trotz schlechter Gesundheit ein Buch erarbeitet. Denn so konnte er mit Peter Gast und seinem Verleger Ernst Schmeitzner einen regen Briefwechsel herbeiführen. Noch in St. Moritz schreibt Nietzsche rückblickend am 11. September 1879: «Die Entsagung in Allem ([sic] - es fehlten Freunde und jeder Verkehr, ich konnte keine Bücher lesen; alle Kunst war ferne von mir; ein Kämmerchen mit Bett, die Speise eines Asketen (die übrigens mir gut gethan hat: keine Magenbeschwerden den ganzen Sommer!) - diese Entsagung war vollständig, bis auf Einen Punkt: ich hieng meinen Gedanken nach - was sollte ich auch thun!» ${ }^{166}$ Dem muss präzisierend hinzugefügt werden, dass Nietzsche sich zwar einsam gefühlt haben mag, jedoch im hochsaisonalen St. Moritz keineswegs alleine war - auch nicht auf den präparierten Spazierwegen.

Am 8. Juni schreibt Nietzsche aus Wiesen an Franz Overbeck: «Schmerz, Einsamkeit, Spazierengehen, schlechtes Wetter - das ist mein Kreislauf. Keine Spur von Aufregung. Vielmehr eine Art gedankenlosen betäubten Übelbefindens $-\gg .167$ 〈Gedankenlos〉 und 〈betäubt〉? Freilich erzählt Nietzsche niemandem von seinem grössten Zeitvertreib - dem Schreiben. Trotz bzw. wegen den aufregungsarmen Spaziergängen hat Nietzsche in St. Moritz viel geschrieben.

Die heterogenen Teile einer Schreibsituation können anhand eines Beispiels aus dem Nachlass von 1879 veranschaulicht werden. Bei meinen Recherchen in Weimar bin ich zufällig auf eine beschriebene Visitenkarte gestossen, die ich aufgrund einer Packliste und einigen Engadiner Informationen dem Jahr 1879 zuordnen konnte (Abb. 9 und 10). So finden sich auf der Vorderseite neben Angaben zu einer Unterkunft in Champfèr, zu Windverhältnissen und zum Gotthard auch der Entwurf zum späteren Aphorismus 242 vom Wanderer. Auf der Rückseite sind Angaben zu drei weiteren Unterkünften, zu den Schreibgeräten («Feder u Halter»), zur Lektüre («Laybruyère», «Carey»), zum Gepäck sowie zur alltäglichen Lebensführung («Klystier», «Feuerversicherung» etc.). Die Materialität der Visitenkarte vereinigt darüber hinaus Affordanzen (Mobilität, Portabilität und Spontaneität). Es finden sich auf kleinstem Raum viele Spuren der Schreibsituation, welche die Aufzeichnung eines philosophischen Gedankens formieren.

sich indeßen mit Prof. Dr. Friedrich Nietzsche trösten, auf dessen angeblichen Tod sich jüngst ein Berliner Recensent berief um zu beweisen, welch' eine gefährliche Sache es sei Wagnerianer zu werden.»» (Elisabeth N. an N., 10.11.1879, Nr. 1253, KGB II 6/2, S. 1218).

166 N. an Gast, 11.9.1879, Nr. 880, KGB II 5, S. 443f.

167 N. an Overbeck, 8.6.1879, Nr. 857, KGB II 5, S. 417. 


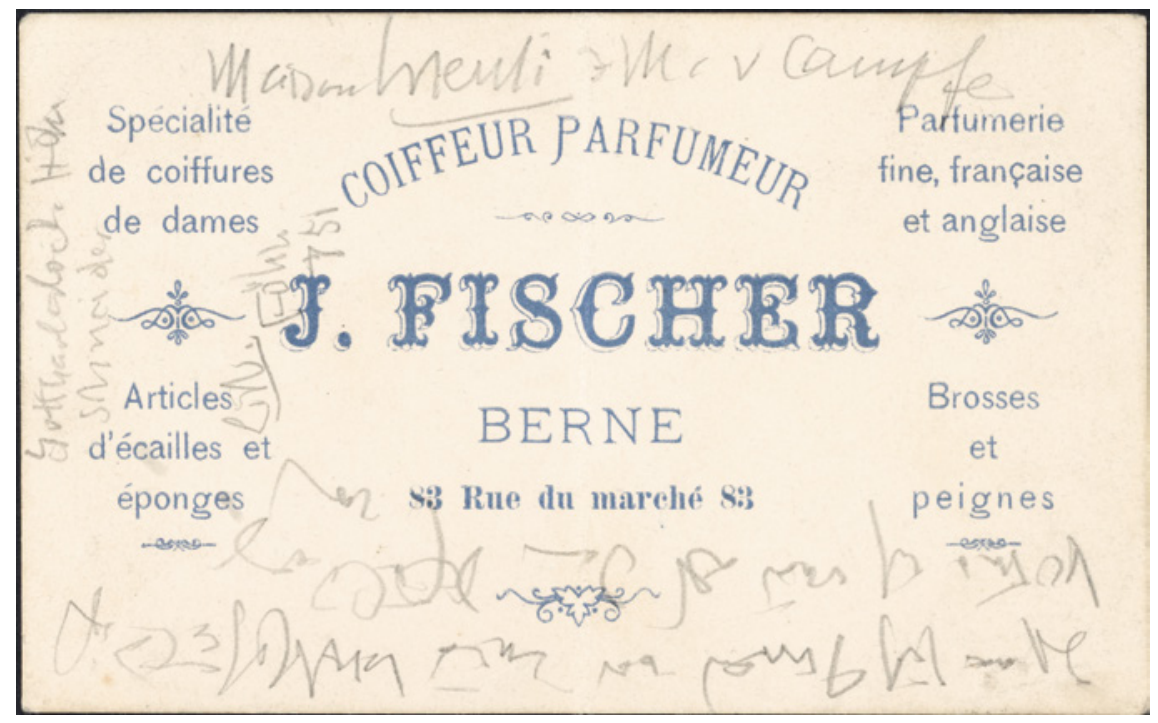

Abb. 9 Vorderseite der Visitenkarte GSA 71/367,1: Blatt 4

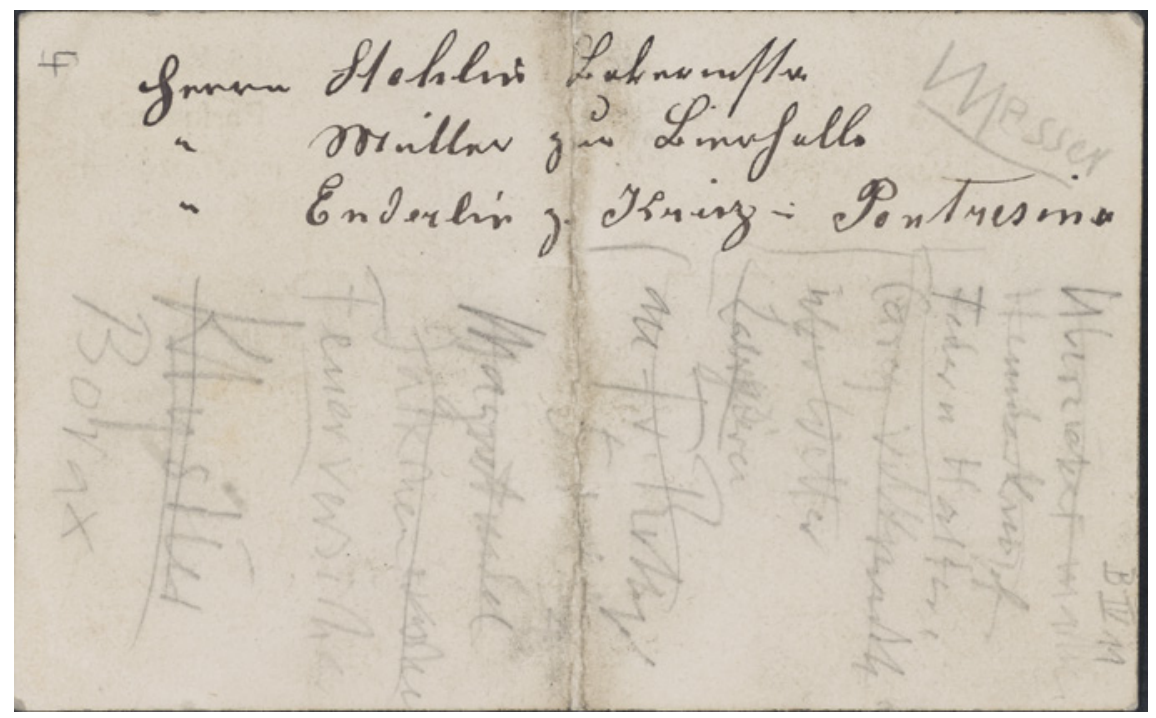

Abb. 10 Rückseite der Visitenkarte GSA 71/367,1: Blatt 4 


\subsubsection{Entstehung des Wanderers}

Die Entstehung des Wanderers wird entlang der folgenden Manuskripte beschrieben: ${ }^{168}$

- Fünf von Nietzsche mit Bleistift beschriebene Oktavhefte mit Notizen (N IV 1-5) und einige Aufzeichnungen mit Tinte in einem anderen Notizbuch (N I $3 \mathrm{c}$ ).

- Zwei Arbeitshefte (M I 2 und 3) mit Umschriften Nietzsches und ein Stapel loser Blätter (Mp XIV 2).

- Das Druckmanuskript (D 13) aus Peter Gasts Reinschrift, die Nietzsche mit der Schere in Zettel schnitt, welche von Ernst Schmeitzner auf Stutzblätter geklebt wurden. 169

- Die korrigierten Druckfahnen (K 6), von denen der zwölfte Bogen fehlt.

\section{Das Notieren und Umschreiben}

Nietzsche berichtet in einem Brief an Peter Gast anschaulich über die erste Phase der Arbeit am Wanderer:

Das Manusc[ript], welches Sie von St. M[oritz] aus bekamen, ist so theuer und schwer erkauft, daß vielleicht um diesen Preis niemand es geschrieben haben würde, der es hätte vermeiden können. Mir graut jetzt öfter beim Lesen, namentl[ich] der längeren Abschnitte, der häßlichen Erinnerung halber. - Alles ist, wenige Zeilen ausgenommen, unterwegs erdacht und in 6 kleine Hefte mit Bleistift skizziert worden: das Um schreiben bekam mir fast jedesmal übel. Gegen 20 län gere Gedankenketten, leider recht wesentliche, mußte ich schlüpfen lassen, weil ich nie Zeit genug fand, sie aus dem schrecklichsten Bleistiftgekritzel herauszuziehen: so wie es mir schon vorigen Sommer gegangen ist. Hinterher verliere ich den Zusammenhang der Gedanken aus dem Gedächtniß: ich habe eben die Minuten und Viertelstunden der «Energie des Gehirns», von der Sie sprechen, zusammenzustehlen, einem leidenden Gehirne a b zustehlen. ${ }^{170}$

Nietzsche notiert in St. Moritz während täglichen Spaziergängen seine Gedanken in sechs Klein-Oktavhefte. Für das Schreiben «unterwegs» benutzt er

168 Vgl. die Manuskriptliste im Literatur- und Quellenverzeichnis.

169 Die Editionsgeschichte löst bei der Benennung bis heute Verwirrung aus. Hans-Joachim Mette hatte es bei seiner ersten Inventur mit «D 12», kurz darauf in der BAW mit «D 13» benannt (Mette 1932, S. 1of.; BAW 1, S. XLII). Die KGW hat letztere Sigle übernommen und mit «D 12» das Druckmanuskript der Vermischten Meinungen bezeichnet (KGW IV 4, S. 106f.). In HyperNietzsche wurde das Druckmanuskript des Wanderers wiederum «D 12» genannt, weshalb einige Publikationen bis heute mit dieser Sigle arbeiten.

170 N. an Gast, 5.10.1879, Nr. 889, KGB II 5, S. 45of. Und kurz nach der Veröffentlichung vom Wanderer teilt er Otto Eiser mit: «Ich kritzele auf meinen Wegen hier und da etwas auf ein Blatt, ich schreibe nichts am Schreibtisch [...].» (N. an Eiser, Anfang Januar 188o, Nr. 1, KGB III 1, S. 4). 
Bleistifte und schreibt, seinem Augenleiden geschuldet, teilweise sehr gross und krakelig. Entgegen der Selbstdarstellung Nietzsches sind mit Sicherheit nicht alle Notate der besagten Notizbücher in St. Moritz und «unterwegs » notiert worden. ${ }^{171}$

Vier der ursprünglich sechs Notizbücher (N IV 1-4) sind erhalten und zugänglich, zwei sind verschollen. ${ }^{172}$ Nietzsche arrangiert seine Notizbücher auf eine spätere Umarbeitung und Publikation hin. Das zeigt sich an seinem Schreibverfahren für die zwei vorhergehenden Aphorismenbücher, den Reinschriften sowie vereinzelten buchkompositorischen Überlegungen. ${ }^{173}$

Ein Teil dieser Notizen wird vermutlich am Abend nacheinander mit Tinte in drei Quarthefte «umgeschrieben»: zuerst in das Heft M I 2, dann in das Heft M I 3 und zuletzt in das Heft Z I 1, wobei letztere Umschriften später herausgerissen werden und heute in einer «Mappe loser Blätter» vorliegen (Mp XIV 2). ${ }^{174}$ Diese drei Hefte beschreibt Nietzsche nacheinander ab Mitte Juli bis zum 10. September: von hinten nach vorne und nur auf den geraden

171 Das zuerst benutzte Notizbuch N IV 2 enthält vereinzelte Notizen von Nietzsches letzter Wegstation Wiesen bei Davos sowie ein Notat über die Gemeinde Schmitten nahe von Wiesen (S. 45-46), vgl. KGW IV 4, S. 562, Fussnote 120.

172 Da für mehr als 7o Aphorismen keine Entwürfe bekannt sind, ist es plausibel, dass ganze zwei Notizbücher fehlen. Vgl. KGW IV 4, S. 107, Fussnote 15: «Da N IV 5 für Hinzufügungen und Änderungen gebraucht wurde, die N im fertigen Druckmanuskript und in den Korrekturen vornahm, und die wenigen Aufzeichnungen zu WS in N I 3 c mit Tinte geschrieben sind, so muss man annehmen, dass 2 der 6 von $\mathrm{N}$ erwähnten Notizbücher uns nicht erhalten sind. Das wird durch den Umstand bestätigt, dass keine Vorstufe zu einem beträchtlichen Teil der Aphorismen von WS nachzuweisen ist.» Auch angesichts der ausformulierten Notate in N IV 5 ist zu vermuten, dass andere Notizen als Vorlage gedient haben.

173 Vgl. Kap. 4.1. Nietzsche dachte bereits in der Notierphase an Schlussmotive eines Buchs, vgl. N IV 2, S. 19; N IV 1, S. 21 bzw. NL 1879, 41[31], KSA 8, S. 588.

174 Glaubt man Nietzsche, dann blieb wegen der langen Spaziergänge nur der Abend zum «Umschreiben», vgl. N. an Elisabeth N., 12.7.1879, Nr. 866, KGB II 5, S. 427; N. an Franziska N., 29.8.1879, Nr. 877, KGB II 5, S. 438. Dass es ein drittes Quartheft gab und es sich dabei um Z I 1 handelt, ergibt sich aus folgenden Hinweisen: Erstens, Nietzsches Hinweis für Gast im Arbeitsheft, dass die Fortsetzung des Schlussdialogs «im Hefte mit grünem Papier» sei, was sich auf die auffällige bläulich-grüne Farbe des Heftpapiers bezieht (M I 3, S. 52). Vgl. auch KGW IV 4, S. 555: «Die Quartblätter bläulicher Färbung sind aus dem Heft Z I 1 herausgerissen». Zweitens, Gasts eigene Anmerkung in seiner Briefausgabe: «diese Sendung an mich bestand aus drei Heften» (GBr 4 S. 445). Drittens, Gasts folgende Briefstelle: «[...] sobald ich das erste Heft copirt habe, werde ich dieses Drittel an Ihre werte Adresse abgehen lassen [...]» (Gast an N., 15.9.1879, Nr. 1230, KGB II 6/2, S. 1165). Ebenso: «Die 3 Hefte von Ihrer eignen Handschrift schicke ich unter Kreuzband nach Naumburg, [...]» (Gast an N., 2.10.1879, Nr. 1235, KGB II 6/2, S. 1173). 
Seiten. ${ }^{175}$ Die leergebliebenen ungeraden Seiten nutzt er für Ergänzungen, welche meist in entsprechender Höhe der Heftseite eingetragen werden. Diese Umschriften sind in viele Textabschnitte, die späteren Aphorismen, strukturiert. Jedoch entspricht die Reihenfolge dieser Abschnitte in keiner Weise der Schlussversion vom Wanderer. Nietzsches Vorgehen ist also auf weitere Bearbeitung hin angelegt.

Bei diesem Arbeitsschritt des Umschreibens baut Nietzsche seine meist kurzen Notate zu längeren Texten aus, korrigiert diese, setzt die Interpunktion und macht Gebrauch von Hervorhebungen mittels Unterstreichung. Nicht selten unterstreicht Nietzsche ein Wort zwei- oder dreifach, obwohl für den Druck nur die einfache Unterstreichung als spätere Sperrung von Belang ist. Inga Gerike beschreibt diese Arbeitsphase wie folgt: «Dabei fügt er neue Überlegungen ein, streicht andere, entwickelt bestimmte Ideengänge, so daß diese Reinschrift weniger eine simple Übertragung ist als vielmehr eine wirkliche Transformation der ersten Entwürfe.» ${ }^{176}$ Zwar zeugen zahlreiche Durchstreichungen und Korrekturen von einer intensiven Textarbeit, es gibt jedoch auch viele wenig bearbeitete Umschriften.

\section{Die Reinschrift von Peter Gast}

Für den nächsten Arbeitsschritt war es nötig, ein sauberes und übersichtliches Manuskript zu haben. Die Arbeitshefte mit ihren mehrfachen Korrekturen hätte Nietzsche nicht übersichtlich lesen und bearbeiten können. Erst durch eine Reinschrift kann er die aktuelle Textversion klar erkennen und zu einem druckfertigen Text weiterentwickeln. Da Nietzsche an starken Sehproblemen leidet und seine Handschrift für die Druckerei nur schwer zu entziffern gewesen wäre, braucht er für die Reinschrift zusätzliche Hilfe. So kann er für den Wanderer einmal mehr auf seinen ehemaligen Studenten und Freund Heinrich Köselitz alias Peter Gast zählen, dessen schöne Handschrift die Korrekturarbeit und die Drucklegung massgeblich vereinfachen. ${ }^{177}$

175 Das erkennt man an der Schreibbewegung und der Paginierung, da Nietzsche M I 2 auf den geraden Seiten von 1-45, M I 3 von 46-91 und Z I 1 von 91-111 durchnummeriert hatte. Laut Nietzsches Datierung in M I 2 wurde dieses Heft ab Mitte Juli mit Umschriften gefüllt (vgl. KGW IV 4, S. 565; M I 2, S. 1: «Juli 1879 Mitte / F. N.»). Aufgrund zweier Datierungen in den Arbeitsheften lässt sich mindestens eine Überarbeitung auf Ende August datieren, vgl. KGW IV 4, S. 565; M I 2, S. 49: «revidirt 28. Aug. 79.»

176 Gerike 2002 bzw. 2000, S. 129.

177 Gast half Nietzsche bereits bei der Druckmanuskripterstellung für Richard Wagner in Bayreuth und Menschliches, Allzumenschliches, vgl. KGW IV 4, S. 97-105. Das Pseudonym «Petro Gasti» bzw. Peter Gast entstand zwar erst 1881, also nach der hier fokussierten Untersuchungsphase. Jedoch ist es aufgrund des weit verbreiteten Pseudonyms bis hin in 
Nietzsche sendet am 10. September drei Quarthefte an Gast. ${ }^{178}$ Tags darauf, am 11. September folgt ein emotionales Begleitschreiben: «Nun werde ich nicht eher ruhig, als bis ich die Blätter, von der Hand des aufopferndsten Freundes geschrieben und durch mich revidirt, nach Chemnitz absenden kann.» ${ }^{179}$ Gast antwortet umgehend mit einem euphorischen «Willkommen Ihrer Sendung!» - und dies obwohl er vom Wanderer bis zu diesem Zeitpunkt nichts weiss, das Begleitschreiben noch nicht erhalten hat und zur Druckmanuskriptherstellung nie angefragt wurde. ${ }^{180}$ Das Verhältnis von Gast zu Nietzsche ist in dieser Zeit geprägt von grosser Verehrung und Liebe, zuweilen gar Unterwürfigkeit. ${ }^{181}$ Gast hofft bei der Ankunft der Arbeitshefte, dass sein hochgeschätzter Professor bald für einen längeren Aufenthalt nach Venedig kommen würde.

So arbeitet Gast dann auch fleissig, sauber und rasch an der Umschrift. Kaum zwei Wochen nach Erhalt der drei Hefte, am 23. September, versendet er die erste Hälfte der Reinschrift an Nietzsche. ${ }^{182}$ In der Zwischenzeit hat Nietzsche St. Moritz verlassen und reist, nach einem Zwischenhalt bei seiner

die Forschungsliteratur praktischer und verständlicher über alle Kapitel hinweg einheitlich von Peter Gast zu sprechen.

178 Das Datum erschliesst sich aus Nietzsches Postkarte vom 12. September: « vorge stern Manuscript, gestern Brief, heute Karte [...].» (N. an Gast, 12.9.1879, Nr. 881, KGB II 5, S. 443).

179 N. an Gast, 11.9.1879, Nr. 880, KGB II 5, S. 442.

180 Gast an N., 12.9.1879, Nr. 1229, KGB II 6/2, S. 1162. Die letzte Korrespondenz zwischen Nietzsche und Gast war eine Postkarte vom 12. Juli und ein Antwortschreiben von Gast am 18. Juli, vgl. Nietzsche an Gast, 12.7.1879, Nr. 865, KGB II 5, S. 426; Gast an N., 18.6.1879, Nr. 1213a, KGB II 7/3,1, S. 11-17.

181 Als «dankbarer und ergebener Schüler» bat Gast, sich an Nietzsches «Umgang läutern zu dürfen.» (vgl. Gast an N., 12.9.1879, Nr. 1229, KGB II 6/2, S. 1163) Eine umfassende Darstellung des Verhältnisses zwischen Nietzsche und Gast findet sich in Love 1981. Gerne hätte Gast in Absprache mit Overbeck versucht, Nietzsche von einem Venedig-Aufenthalt zu überzeugen. Gasts Verehrung für Nietzsche in dieser Phase zeigt sich auch in seinem Briefwechsel mit Cäcilie Gussenbauer, in dem er über Nietzsche u.a. schreibt: «er ist ein Heiliger im feierlichsten Sinne» (11./12.7.1879, zit. n. Krummel/Krummel 1994, S. 338). Und weiter: «so wie ihn habe ich noch keinen Mann geliebt, selbst meinen Vater nicht, um aufrichtig zu sein,... mir ist, als wär' es meine schönste Pflicht, mit ihm zu sterben.» (12.9.1879, zit. n. Krummel/Krummel 1994, S. 339) Trotzdem war dies nur eine Phase, weil Gast dann 1880 merkt, wie anstrengend die ständig dienende Freundschaft wirklich ist: «Ich ließe am liebsten Nietzsche allein von hier fortgehen und bliebe den ganzen Sommer hier, um wieder soviel als möglich nachzuholen, was ich nun zum Himmelmillionendonnerwetter an Zeit, Kraft, Gedankenzusammenhaltung und allem Möglichen sonst verloren habe. Nietzsches Gegenwart occupirt mich zu viel.» (28.5.188o, zit. n. Krummel/ Krummel 1994, S. 347f.).

182 Vgl. Gast an N., 23.9.1879, Nr. 1231, KGB II 6/2, S. 1166. 
Schwester Elisabeth in Chur, am 2o. September nach Naumburg. Nietzsche hat in der Zwischenzeit weitergeschrieben und sendet die letzten losen Blätter mit zusätzlichen Texten nach Venedig. ${ }^{183}$ Seinen Umzug meldet er Gast erst nach der Ankunft in Naumburg, weshalb der schnelle Gast einen Teil der Reinschriften bereits nach St. Moritz verschickt hat, von wo aus sie erst am 3. Oktober in Naumburg eintreffen. ${ }^{184}$ Am selben Tag erreicht Nietzsche die zweite Hälfte der Reinschrift und bereits am 4. Oktober jene der nachgesandten losen Blätter. ${ }^{185}$ Nietzsche bedankt sich am 5. Oktober bei Gast für die Sendung. Gasts Vorschlag, den Wanderer noch mit unverwendeten Notaten aus den Sorrentiner Manuskripten anzureichern, lehnt Nietzsche mit Verweis auf deren Verschwinden ab. ${ }^{186}$

Am selben Tag schreibt Nietzsche seinem Verleger Ernst Schmeitzner, der bis dato noch nichts vom Wanderer wusste: «im Frühjahre fragten Sie bei mir an, ob es am Jahres-Ausgange ein M[anu]sc[ript] geben werde: Sie fügten Fragezeichen und Ausrufezeichen hinzu - und heute thue ich dasselbe, wo ich Ihnen melde, daß es ein Msc. giebt - ?! ich glaube es selber kaum.»187

183 Es ist nicht restlos aufzuklären, welches die «letzten Blätter aus dem Engadin» sind, die Nietzsche am 30. September aus Naumburg an Gast sandte (N. an Gast, 30.9.1879, Nr. 887, KGB II 5, S. 448). Es kann sich bei diesen losen Blättern nicht um die Mappe Mp XIV 2 handeln, in der heute lose Blätter mit Wanderer-Entwürfen vorliegen. Diese losen Blätter bläulicher Färbung gehörten damals noch zum Heft Z I 1, und wurden wohl erst später herausgerissen (vgl. KGW IV 4, S. 555). Ich vermute deshalb, dass es sich bei diesen letzten «Blättern» um alle losen Blätter handelt, die nicht im Format eines der drei Hefte vorliegen. Für diese Interpretation spricht auch die Tatsache, dass im Druckmanuskript zwei Reinschriften von Gast zusammengeklebt sind, die zum selben Aphorismus gehören (D 13, Blatt 10 recto; WS 17, KSA 2, S. 551). Nietzsche hat den zweiten Teil auf ein loses Blatt geschrieben, das exakt dem hinzugeklebten Teil entspricht (Mp XIV 2, Blatt 49, recto). Wäre dieser zweite Teil nicht nachgesandt worden, hätte Gast ihn sogleich an einem Stück schreiben können. Es ist zudem wahrscheinlich, dass Nietzsche nach seiner Ankunft in Naumburg die von ihm kritisierte Schopenhauer-Stelle nachlas und entsprechend erweiterte.

184 Vgl. N. an Gast, 4.10.1879, Nr. 888, KGB II 5, S. 449.

185 Die Daten erschliessen sich aus der Korrespondenz zwischen Nietzsche und Gast: «Gestern (Freitag) kam Ihre Abschrift des Ganzen in meine Hände [...].» (N. an Gast, 4.10.1879, Nr. 888, KGB II 5, S. 449) Gast hatte das «Uebrige des Manuscripts» am 2. Oktober von Venedig aus nach Naumburg gesendet (Gast an N., 1./2.10.1879, Nr. 1235, KGB II 6/2, S. 1172). Vgl. die im folgenden Brief erwähnte Ankunftsbestätigung: N. an Gast, 5.10.1879, Nr. 889, KGB II 5, S. 450: «Gestern Nachmittag lief meine Karte an Sie, lieber Freund, ab, und drei Stunden später hatte ich wieder neue Beweise Ihrer unermüdlichen Güte für mich in den Händen.»

186 Vgl. N. an Gast, 5.10.1879, Nr. 889, KGB II 5, S. 451. Es ist unklar, welches Manuskript Nietzsche hier meint, da die Aufzeichnungen aus Sorrent sowie das Druckmanuskript von Menschliches erhalten sind, vgl. KGB II 7/3,1, S. 419.

187 N. an Schmeitzner, 5.10.1879, Nr. 89o, KGB II 5, S. 452f. 
Leider ist das Antwortschreiben von Schmeitzner nicht erhalten. Es ist aufgrund der schnellen und unkomplizierten Abwicklung aber davon auszugehen, dass er rasch antwortet. Dass Schmeitzner trotz der negativen Verkaufszahlen von Menschliches und den Vermischten Meinungen umgehend auf das neue Publikationsvorhaben reagiert, ist auch dem erfolgreichen Schriftsteller und früheren Kritiker der Unzeitgemässen Betrachtungen, Karl Hillebrand (18291884), zu verdanken. Hillebrand prognostiziert Schmeitzner im Juli 1879, dass Nietzsche mit einer Verzögerung von 10-15 Jahren grosse Nachfrage finden würde (was tatsächlich eintraf). ${ }^{188}$

Übrigens weiss wohl ausser Gast, der erst mit der Bitte um die Reinschrift vom Wanderer erfuhr, niemand von Nietzsches Buchvorhaben. In seinen Briefen lassen sich keine Bemerkungen finden, die auf eine Schreibtätigkeit hindeuten. Nietzsche hat im Geheimen geschrieben und erst im letzten Moment die für die weiteren Arbeitsschritte notwendigen Personen kontaktiert: Gast für die Abschrift, Schmeitzner für Druck und Verlag. Dies belegt auch eine Postkarte, die Nietzsche einen Tag nach der Manuskriptübersendung vom 11. September an Gast sendet: «Bewahren Sie das Geheimniß des Manuscr[ipts] und meiner Winterpläne bis auf Weiteres vor J e d e r m a n n! Auch Prof. O[verbeck] weiß noch nichts.» ${ }^{189}$ Dies, obwohl der treue Freund Overbeck der einzige Besucher während des Aufenthalts in St. Moritz ist.

\section{Mit der Schere zum Druckmanuskript}

Gemäss bisherigen Erkenntnissen schneidet Nietzsche mit der Schere die Reinschriften von Gast auseinander. Danach legt er die losen Zettel als Stapel in halbgefaltete Papiere mit lateinischen Überschriften, die sich an den neun Hauptstücken von Menschliches orientieren: so etwa «I Metaphysica» oder «II Moralia» (Abb. 11 und 12). 190 Bei diesem Arbeitsschritt des Bündelns und Stapelns der Zettel korrigiert Nietzsche die Texte und gibt jedem Aphorismus

188 Hier der Wortlaut: «Ich weiß, es ist ein schlechtes Geschäft, gediegene Autoren zu geben, allein es zählt doch, freilich spät, aber dann um so sicherer: in zehn, fünfzehn Jahren werden Nietzsche's Schriften eine gewaltige Nachfrage finden, daher seien Sie sicher und verlieren Sie den Muth nicht.» (KSA 15, S. 107).

189 N. an Gast, 12.9.1879, Nr. 881, KGB II 5, S. 443f. Am 11. Dezember, also erst eine Woche vor Versendung der Freiexemplare, macht Nietzsche gegenüber Overbeck eine Andeutung auf den Wanderer, die dieser zu dem Zeitpunkt aber nicht verstehen kann: «Nächste Woche trifft M. Twain bei Dir ein, ebenso eine Erinnerung an meinen St. Moritzer Aufenthalt» (N. an Overbeck, Nr. 913, KGB II 5, S. 470). Mit der einzutreffenden «Erinnerung» ist der Wanderer gemeint.

190 Das ganze Verfahren der Zettelzuordung ähnelt der Praxis eines Herausgebers, der nachgelassene Notate thematisch sortiert. Mein herzlicher Dank geht an Paolo D'Iorio für das ergiebige Gespräch über die Entstehung des Druckmanuskripts. 
einen Titel. Er fügt sogar noch einige neue Aphorismen hinzu, die aufgrund seiner Handschrift im Druckmanuskript einfach zu erkennen sind. ${ }^{191}$ Die lateinischen Überschriften sind Arbeitsinstrumente, die Nietzsche explizit nicht abgedruckt haben will. ${ }^{192}$ Im Vergleich zu den literarisch stilisierten Hauptstücktiteln von Menschliches sind die lateinischen Überschriften Ordnungskategorien zur Bündelung der Aphorismenzettel.

Das Druckmanuskript wird in weniger als zwei Wochen fertiggestellt und am 18. Oktober fährt Nietzsche persönlich von Naumburg nach Leipzig, um seinem Verleger, der aus Chemnitz anreist, das Zettelmanuskript, d.h. den Stapel der in Falzblätter eingefassten Zettel, zu übergeben. ${ }^{193}$ Colli und Montinari gehen sogar davon aus, dass Nietzsche allenfalls die Anordnung der Aphorismen erst in Leipzig zusammen mit seinem Verleger vornimmt. ${ }^{194}$ Es war Schmeitzner, der diesen Zettelstapel dann der Reihe nach auf Stutzblätter klebt und so das Druckmanuskript, wie es heute vorliegt, erstellt. ${ }^{195}$ Wie in den Abbildungen zu sehen ist, hat Schmeitzner offenbar einige der Falzblätter als Stutzblätter verwendet (Abb. 11 und 12 ). ${ }^{196}$

Dies ist im Übrigen schon die Vorgehensweise für die im März desselben Jahres abgeschlossenen Arbeiten an den Vermischten Meinungen. Schmeitzner bekommt damals die losen Zettel als «Zettel-Manuscript» zugesendet und berichtet: «Die Zettel werden hier aufgeklebt und wandern [sic] die ersten Bogen

191 Aphorismen von Nietzsches Handschrift in D 13: WS 17, WS 20, WS 71, WS 73, WS 308; grössere Textergänzungen von Nietzsches Hand finden sich in D 13 bei WS 16, WS 86, WS 93, WS 216, WS 282, WS 285 , WS 338.

192 Vgl. die Aufschrift «Metaphysica» vom ersten Falzblatt: «ohne Ueberschriften» (Abb. 11). Vgl. auch die Gründe für eine erhöhte Eigenständigkeit (vgl. Kap. 2.2) sowie den lockeren Stil, der sich auch in einer losen Gliederung manifestierte (Kap. 3.2.2).

193 Bei der Übergabe war auch Paul Heinrich Widemann zugegen, der mit Gast 1876 Vorlesungen von Nietzsche besucht hatte und auch den ersten Kontakt zwischen Nietzsche und Schmeitzner herstellte, vgl. Reich 2004, S. 236.

194 Diese Vermutung stützt sich auf das Stichwort «Anordnung» in Nietzsches Notizbuch N IV 5, S. 5o. Vgl. KGW IV 4, S. 572, Fussnote 134: «Zum letzten Stichwort sei bemerkt, dass $\mathrm{N}$ die Nummerierung und Anordnung des Dm zu WS mit Schmeitzner zusammen in Leipzig vornahm [...].» Es ist unwahrscheinlich, dass Nietzsche zusammen mit Schmeitzner, der die Inhalte nicht kannte und philosophischer Laie war, die Anordnung machte. Zudem hatten sie in Leipzig wenig Zeit, da Nietzsche ankündete, aus gesundheitlichen Gründen nur für kurze Zeit ein Treffen ertragen zu können, vgl. N. an Schmeitzner, 15.10.1879, Nr. 892, KGB II 5, S. 454 f.

195 Den Ausdruck «Stutzblätter» übernehme ich von d'Alfonso/Saller 2007.

196 Damit ist folgende Aussage von Gerike falsch: «Nietzsche geht nun an die nächste Etappe der Textentstehung: er nimmt Schere und Leim, schneidet die von Gast abgeschriebenen Aphorismen aus und klebt sie auf Foliobögen in der Reihenfolge, die schließlich auch die des gedruckten Textes sein wird.» (Gerike 2002 bzw. franz. 2000, S. 130). 


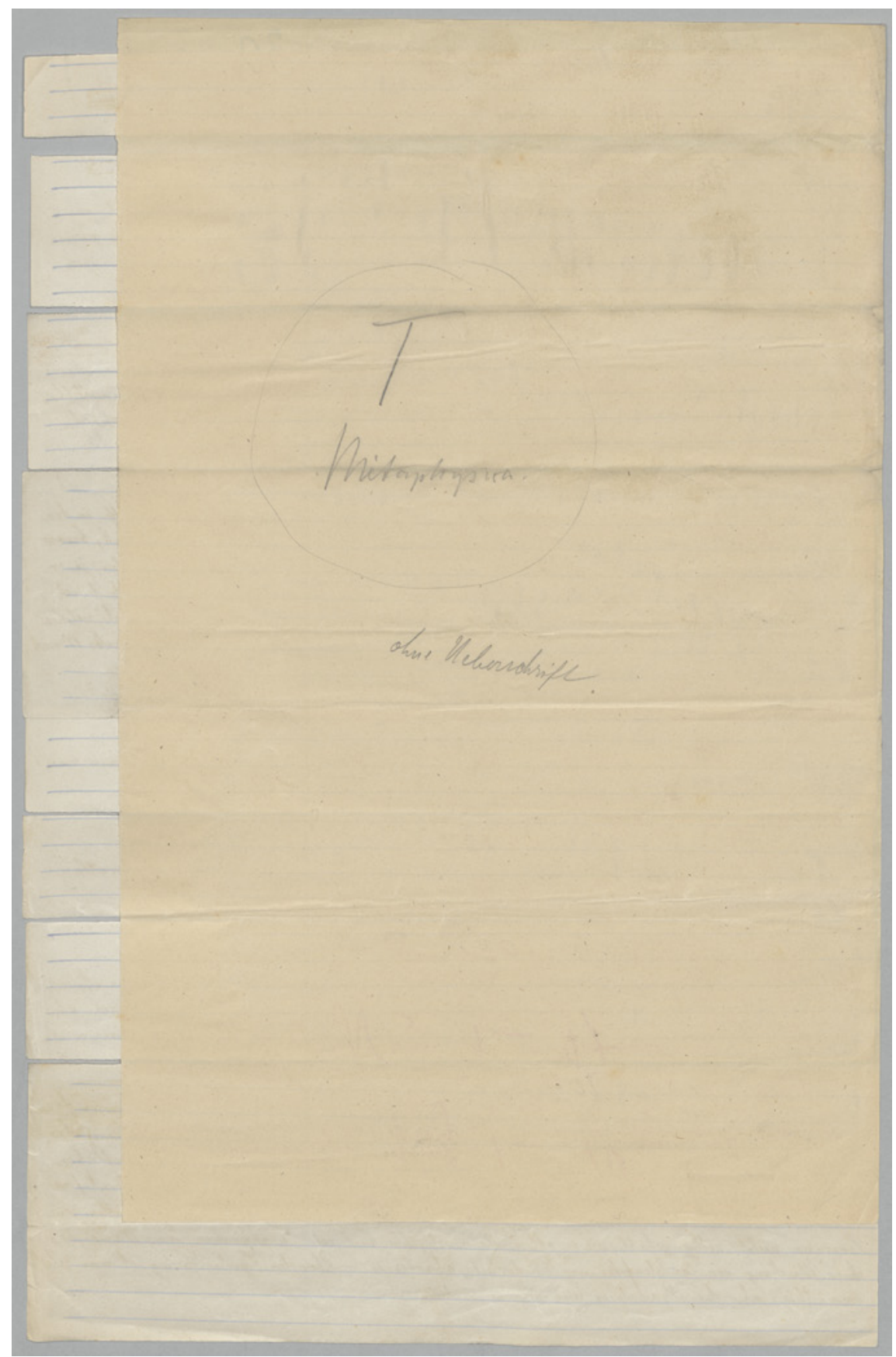

Abb. 11 Druckmanuskript D 13, Blatt 30 verso: «I Metaphysica» 


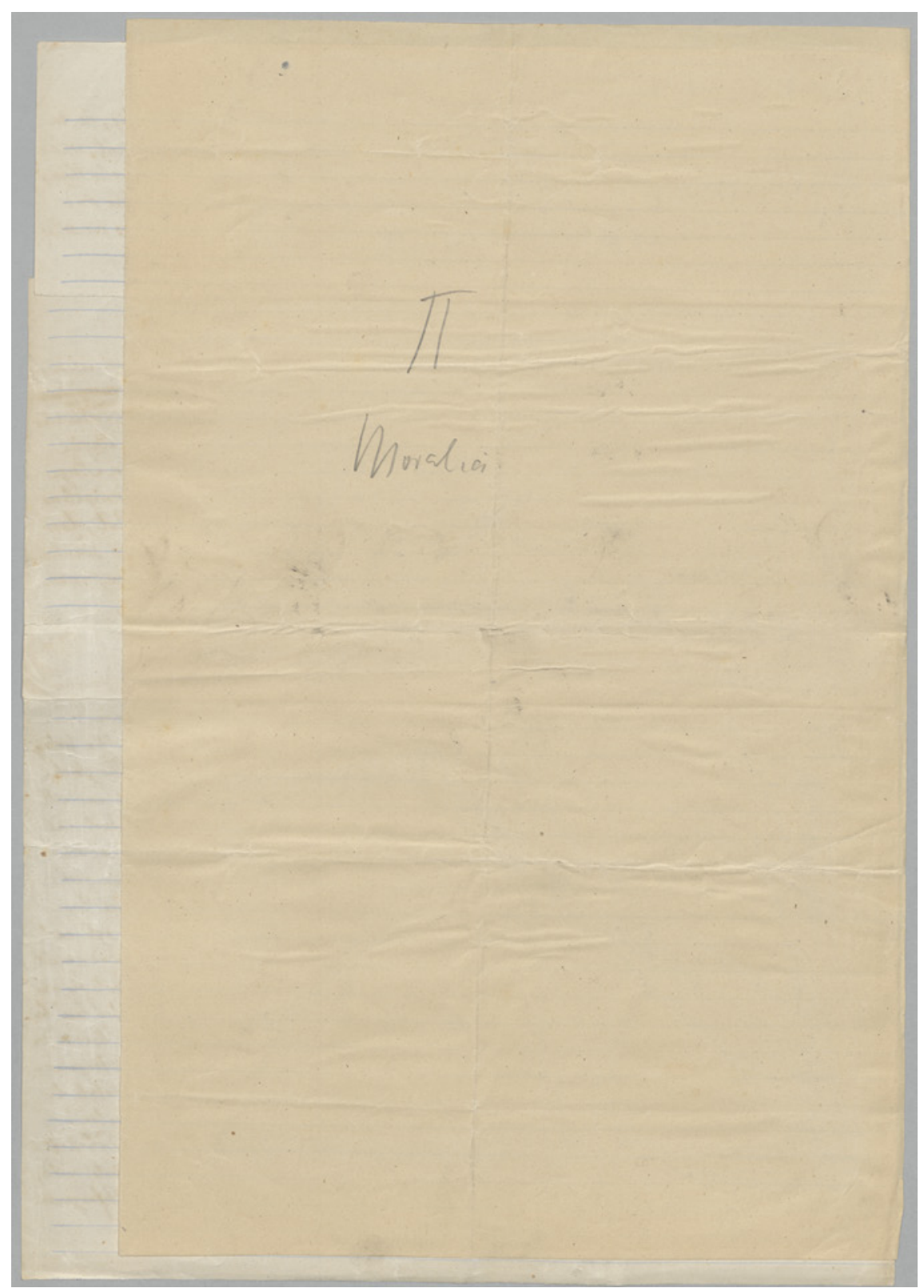

Abb. 12 Druckmanuskript D 13, Blatt 27 verso: «II Moralia» 
heut Abend noch zur Druckerei.»197 Während dieser Drucklegung reicht Nietzsche noch einen weiteren Spruch nach: «Dann bitte, fügen Sie noch irgendwo einen meiner 〈Sprüche〉 ein, auf den ich mir etwas zu Gute thue [...].»198 Nietzsche überlässt Schmeitzner die Entscheidung, wobei das «irgendwo» zur zufälligen Einreihung auffordert. Man beachte nun Nietzsches Wortwahl, als er Schmeitzner im Oktober 1879 noch einen zusätzlichen Aphorismus für den Wanderer nachsendet: «Wollen Sie, lieber Herr Schmeitzner, dies noch unter die Religiosa (III) einreihen?» ${ }^{199}$ Mit «Religiosa (III)» meint Nietzsche eines der Falzblätter, in welche er die Aphorismen-Zettel einordnete. Der Ausdruck «einreihen» bezieht sich eher auf einen Zettelstapel, als auf ein geklebtes Manuskript. Offenbar weiss Nietzsche nicht, in welcher Reihenfolge er die Zettel gestapelt hat.

\section{Von der Korrektur bis zur Publikation}

In der Folge werden in der Druckerei Richard Oschatz in Chemnitz die Druckbogen hergestellt. Gast hilft bei der Korrektur. ${ }^{200}$ Da der Wanderer im Oktav-Format gedruckt wird, umfasst jeder Druck- bzw. Korrekturbogen 16 Buchseiten. Wegen der begrenzten Anzahl Setzbuchstaben in der Druckerei sowie den weit auseinanderliegenden Akteuren - Schmeitzner in Chemnitz, Nietzsche in Naumburg, Gast in Venedig - muss die Korrektur in einem koordinierten Turnus erfolgen: Es werden 2-3 Druckbogen gleichzeitig hergestellt, die anfangs über Nietzsche zu Gast, später direkt zu Gast nach Venedig versendet werden. ${ }^{201}$ Gast korrigiert sein Exemplar des Druckbogens und sendet es

197 Schmeitzner an N., 3.1.1879, Nr. 1140, KGB II 6/2, S. 1014. Das Wort «Z ettel-Manuscript» ist von Nietzsche (vgl. N. an Schmeitzner, 31.12.1878, Nr. 789, KGB II 5, S. 377). Auch später scheint Nietzsche die Technik des Falzblattes zu verwenden: So hat das Blatt 422 aus der Mappe «Mp XIV» den mittigen Titel «Masken» und ebenfalls einen Falz. Es ist naheliegend, dass Nietzsche in diesem Falzblatt die Texte zum ursprünglich geplanten Hauptstück «Masken» von Jenseits von Gut und Böse stapelte. Diesen Hinweis verdanke ich Beat Röllin.

198 N. an Schmeitzner, 12.1.1879, Nr. 795, KGB II 5, S. 380.

199 N. an Schmeitzner, 22.10.1879, Nr. 895, KGB II 5, S. 457.

200 Vgl. KGW IV 4, S. 106f. Für die Mithilfe an der Korrektur hatte sich Gast bereits im Voraus anerboten, vgl. Gast an N., 1./2.10.1879, Nr. 1235, KGB II 6/2, S. 1173: «Beim Druck biete ich Ihnen natürlich wieder meine Dienste als Corrector an.»

201 Diese Vermutung ergibt sich aus den Hinweisen für die Druckbogen 1-3, welche von Schmeitzner an Nietzsche versendet wurden (N. an Schmeitzner, 27.10.1879, Nr. 897, KGB II 5, S. 458f.; Schmeitzner an N., 28.10.1879, Nr. 1247, KGB II 5, S. 1200). Anders sieht es beim 11. Druckbogen aus, der gemäss Schmeitzner direkt an Gast geht (vgl. Schmeitzner an N., 28.11.1879, Nr. 1259, KGB II 6/2, S. 1231). Leider gibt es für die Druckbogen 
zuweilen mit zusätzlichen inhaltlichen Vorschlägen zurück an Nietzsche. Dieser trägt seine eigenen Korrekturen in Gasts Korrekturbogen ein und sendet diesen schnellstmöglich an Schmeitzner zurück, der die korrigierten Druckbogen in entsprechender Auflage drucken lässt. Danach werden die freigewordenen Setzbuchstaben umgehend für den nächsten Druckbogen eingesetzt usw. Der überlieferte Korrekturbogen K 6 von 1879 ist folglich nicht von Nietzsche imprimiert, sondern enthält nur einen Teil der Korrekturen. ${ }^{202}$ Nietzsche und Gast erhalten dann die Aushängebogen der gedruckten Auflage der je abgeschlossenen Bogen. Da zu diesem Zeitpunkt keine Änderungsmöglichkeit mehr besteht, macht Gast die Kollation, also den Abgleich von Drucktext und Druckmanuskript. Aus dieser Arbeit entsteht das Druckfehlerverzeichnis vom Wanderer, welches vier Fehler aufführt.

Ab Mitte November beginnen bereits die Publikationsvorbereitungen:Nietzsche sendet Schmeitzner die Namensliste für Freiexemplare und Schmeitzner arbeitet mit Gast an einer Verlagsbroschüre. ${ }^{203}$ Sie enthält neben einem kurzen Vorwort von Schmeitzner die von Gast geschriebenen Abstracts der bisher im Verlag erschienenen Bücher. Ebenfalls im November bittet Nietzsche um

dazwischen wenig Informationen. Jedenfalls scheint sich das Verfahren geändert zu haben. Gemäss Montinaris Beschreibung der Drucklegungen von Nietzsches Büchern, wurde jeweils gleichzeitig ein Druckbogen an Nietzsche (Cb1) und Gast (Cb2) gesendet. Die KGW nennt den zusammengeführten Korrekturbogen dann «Cbi», weil nur dieser mit Druckerlaubnis an den Verlag ging (vgl. Montinari 1988b, S. 482f.). Dem entspricht auch die Produktionsweise von Menschliches, bei dessen Korrekturarbeiten Nietzsche folgende Anweisung an Schmeitzner gab: «Also 1 Bogen immer an mich nach Baden, der andre nach Basel an Hr. Köselitz.» (N. an Schmeitzner, 11.3.1878, Nr. 690, KGB II 5, S. 306).

202 Es handelt sich in der beschriebenen Logik um «Cb1» vom Wanderer, da nicht alle Korrekturen von K6 im Drucktext sind. Nietzsche trug in einem separaten Arbeitsschritt die finalen Korrekturen in Gasts Korrekturbogen ein. Vgl. etwa die sprachlichen Unterschiede zwischen der Druckfassung vom Aphorismus 57 (WS 57, KSA 2, S. 577) und den entsprechenden Zusätzen und Korrekturen im Korrekturbogen (K 6, S. 49a). Zudem sind in K6 hauptsächlich Schreibspuren Nietzsches zu finden.

203 Vgl. N. an Schmeitzner, 22.11.1879, Nr. 907, KGB II 5, S. 466. Vgl. auch KGB II 7/3,2, S. 1112. Der 16-seitige Text unter dem Titel «Erster Verlagsbericht der Verlagsbuchhandlung» wurde neben einem Separatdruck auch der Erstpublikation vom Wanderer angehängt. Der Separatdruck ist schwierig zu datieren. Schmeitzner scheint ihn sukzessive ab Anfang Dezember versendet zu haben. Nietzsche erhielt eine Woche vor Versendung des Wanderers ein Exemplar davon, vgl. N. an Overbeck, 11.12.1879, Nr. 913, KGB II 5, S. 470. Schmeitzner spricht von 15'00o Exemplaren (vgl. Schmeitzner an N., 12.12.1879, Nr. 1262, KGB II 6/2, S. 1235). 
die Überweisung des Autorenhonorars, das sich nach der Anzahl Druckbogen richtet. 204

Am 7. Dezember sendet Nietzsche den letzten Korrekturbogen an Schmeitzner. ${ }^{205} \mathrm{Am}$ 12. Dezember ist der Wanderer fertig gedruckt und damit bereit für die Buchbindung. ${ }^{206}$ Die Erstausgabe erscheint noch im Dezember 1879 in einer Auflage von 1000 Exemplaren im Oktavformat, kostet 6 Mark und hat einen hellgrauen Pappumschlag. ${ }^{207}$ Die Seitenanzahl des Haupttextes beträgt 185 Seiten mit 350 Aphorismen, wobei 1 Seite Berichtigungen und 18 Seiten Verlagsbericht hinzukommen. ${ }^{208}$ Das Publikationsdatum wird mit 1880 gedruckt. ${ }^{209}$

Nietzsche bekommt sein Buch am 18. Dezember zugeschickt: «Der vollendete «Wanderer ist mir fast etwas Unglaubliches - am 21. Juni kam ich nach St. Moritz - und heute - !» ${ }^{210}$ Es ist davon auszugehen, dass auch die anderen Freiexemplare im selben Zuge verteilt werden. Für den Buchhandel soll der Wanderer erst Ende Februar 1880 ausgeliefert werden, da jeweils im Frühjahr die Leipziger Buchmesse stattfand. Trotzdem hat Schmeitzner schon Ende Dezember 700 der 1000 Exemplare versendet.

In der von mir erstellten Übersicht sieht die Rekonstruktion der Entstehung vom Wanderer zwischen dem 21. Juni und dem 18. Dezember wie folgt aus:

204 Vgl. N. an Schmeitzner, 18.11.1879, Nr. 906, KGB II 5, S. 465. Das Honorar für 11 9/16 Druckbogen bzw. 185 Seiten betrug 346.88 Mark (vgl. Schmeitzner an N., 4.12.1879, Nr. 1261, KGB II 6/2, S. 1235). Ausbezahlt wurden aber 133.14 Mark, weil Nietzsche über Schmeitzner im Sommer zwei Bücher sowie eine 197.40 Mark teure Staatsanleihe gekauft hatte, die vom Honorar abgezogen wurden.

205 Vgl. N. an Schmeitzner, 7.12.1879, Nr. 911, KGB II 5, S. 469 und die Präzisierung im Kommentarband KGB II 7/3,1, S. 437: «Beilage: der letzte Korrekturbogen zu «Der Wanderer und sein Schatten»».

206 «Hochgeehrter Herr Professor! Heute wird der «Wanderer〉 ausgedruckt, die letzten Aushängebogen schicke ich Ihnen, sobald ich sie aus der Druckerei erhalte.» (Schmeitzner an N., 12.12.1879, Nr. 1262, KGB II 6/2, S. 1235).

207 Vgl. Schaberg 2002, S. 109. Der Wanderer hat bei einem Satzspiegel von $94 \times 166 \mathrm{~mm}$ 32 Zeilen pro Seite. Noch in Menschliches waren es bei $94 \times 171 \mathrm{~mm} 33$ Zeilen pro Seite und in früheren Publikationen bei $95 \times 165 \mathrm{~mm}$ immer 33 Zeilen.

208 Vgl. ebd. Beachtet man Nietzsches Konnotation der Manuskriptsendung mit seinem 35. Geburtstag, könnte die Zahl von 350 Aphorismen absichtlich gewählt sein (vgl. N. an Gast, 11.9.1879, Nr. 880, KGB II 5, S. 441).

209 Diese Setzungen für spät im Jahr erscheinende Bücher sind bis heute im Buchhandel gebräuchlich.

$210 \quad$ N. an Schmeitzner, 18.12.1879, Nr. 915, KGB II 5, S. 471. 


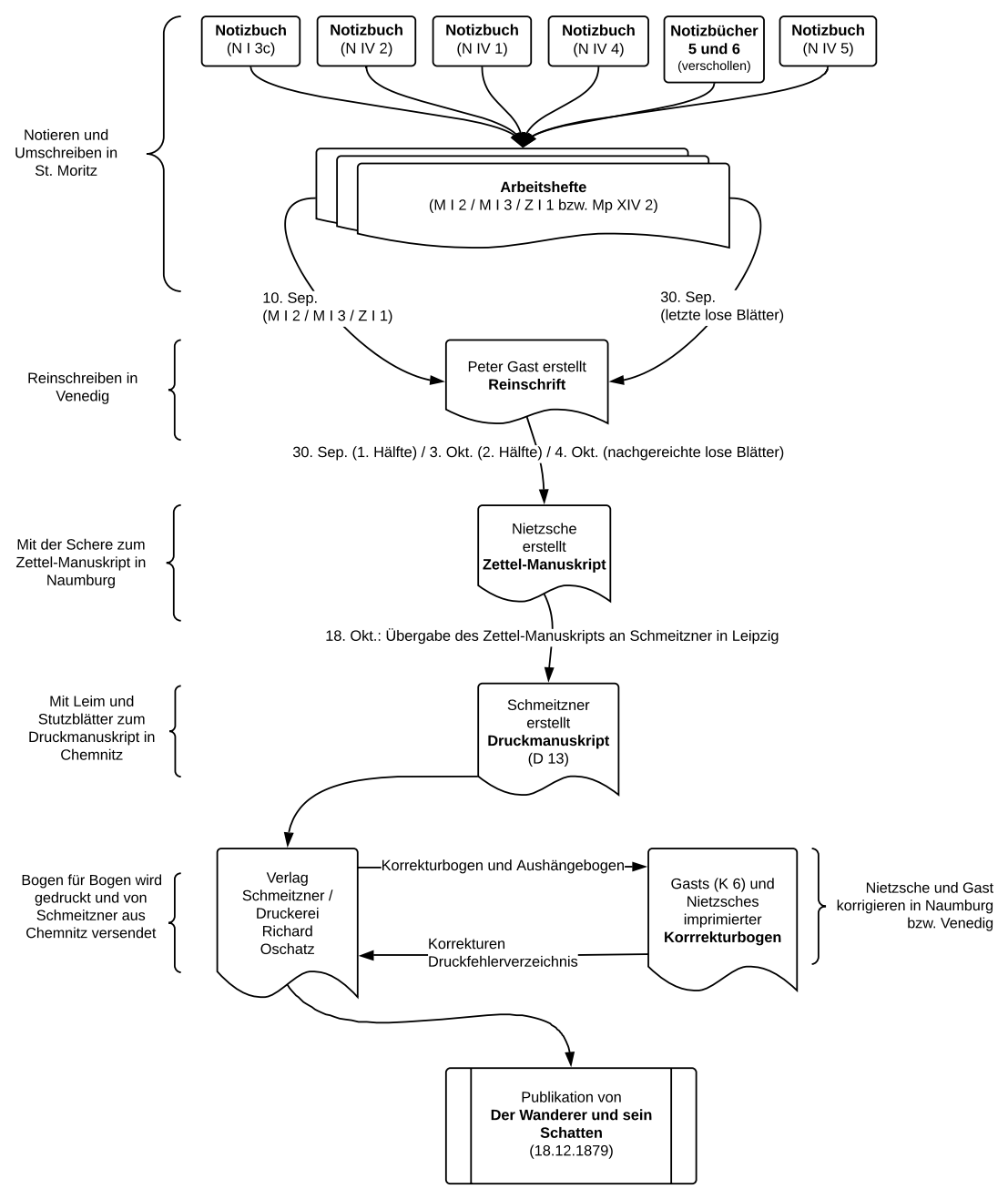

